\title{
Reconstruction of the Mars Science Laboratory Parachute Performance and Comparison to the Descent Simulation
}

\author{
Juan R. Cruz, ${ }^{1}$ David W. Way, ${ }^{2}$ Jeremy D. Shidner, ${ }^{3}$ Jody L. Davis ${ }^{4}$ \\ NASA Langley Research Center, Hampton, Virginia, 23681 \\ and \\ Douglas S. Adams, ${ }^{5}$ Devin M. Kipp ${ }^{6}$ \\ Jet Propulsion Laboratory, Pasadena, California, 91109
}

\begin{abstract}
The Mars Science Laboratory used a single mortar-deployed disk-gap-band parachute of $21.35 \mathrm{~m}$ nominal diameter to assist in the landing of the Curiosity rover on the surface of Mars. The parachute system's performance on Mars has been reconstructed using data from the on-board inertial measurement unit, atmospheric models, and terrestrial measurements of the parachute system. In addition, the parachute performance results were compared against the end-to-end entry, descent, and landing (EDL) simulation created to design, develop, and operate the EDL system. Mortar performance was nominal. The time from mortar fire to suspension lines stretch (deployment) was $\mathbf{1 . 1 3 5} \mathrm{s}$, and the time from suspension lines stretch to first peak force (inflation) was $0.635 \mathrm{~s}$. These times were slightly shorter than those used in the simulation. The reconstructed aerodynamic portion of the first peak force was $153.8 \mathrm{kN}$; the median value for this parameter from an 8,000-trial Monte Carlo simulation yielded a value of $175.4 \mathrm{kN}-14 \%$ higher than the reconstructed value. Aeroshell dynamics during the parachute phase of EDL were evaluated by examining the aeroshell rotation rate and rotational acceleration. The peak values of these parameters were $69.4 \mathrm{deg} / \mathrm{s}$ and $625 \mathrm{deg} / \mathrm{s}^{2}$, respectively, which were well within the acceptable range. The EDL simulation was successful in predicting the aeroshell dynamics within reasonable bounds. The average total parachute force coefficient for Mach numbers below 0.6 was 0.624, which is close to the pre-flight model nominal drag coefficient of 0.615 .
\end{abstract}

\footnotetext{
${ }^{1}$ Aerospace Engineer, Atmospheric Flight and Entry Systems Branch, Juan.R.Cruz@NASA.gov, AIAA Member.

${ }^{2}$ Aerospace Engineer, Atmospheric Flight and Entry Systems Branch, David.W.Way@NASA.gov, AIAA Member.

${ }^{3}$ Aerospace Engineer, Atmospheric Flight and Entry Systems Branch, Binera, Inc., Yorktown, Virginia, Jeremy.D.Shidner@NASA.gov, AIAA Member.

${ }_{5}^{4}$ Aerospace Engineer, Atmospheric Flight and Entry Systems Branch, Jody.L.Davis@NASA.gov, AIAA Member.

${ }^{5}$ Senior Systems Engineer, Spacecraft Structures and Dynamics Group, Douglas.S.Adams@JPL.NASA.gov, AIAA Member.

${ }^{6}$ Systems Engineer, EDL Systems and Advanced Technologies Group, Devin.M.Kipp@JPL.NASA.gov, AIAA Member.
} 


\section{Nomenclature}

\begin{tabular}{|c|c|c|c|}
\hline$a_{A S}$ & $=$ total sensed aeroshell acceleration at its & $q_{\infty}$ & $=$ dynamic pressure \\
\hline & center of mass & $S_{B}$ & $=$ band area \\
\hline$C_{D_{0}}$ & $=$ parachute drag coefficient & $S_{D}$ & $=$ disk area \\
\hline$C_{N}$ & $=$ parachute normal force coefficient & $S_{G}$ & $=$ gap area \\
\hline & (total/axisymmetric) & $S_{0}$ & $=$ parachute nominal (reference) area \\
\hline$C_{T}$ & $=$ parachute tangential force coefficient & $S_{V c}$ & $=$ constrained vent area \\
\hline$C_{\text {Tot }_{0}}$ & $=$ total parachute force coefficient & $S_{V u}$ & $=$ unconstrained vent area \\
\hline$C_{X}$ & $=$ opening load factor & $T_{\infty}$ & $=$ atmospheric temperature \\
\hline$D_{A S}$ & $=$ aeroshell diameter & $t$ & $=$ time \\
\hline$D_{B}$ & $=$ band diameter & $\alpha_{A S}$ & $=$ aeroshell angle of attack assuming no \\
\hline$D_{D}$ & $=$ disk diameter & & wind \\
\hline$D_{P}$ & $=$ projected diameter & $\alpha_{A S, T o t}$ & $=$ aeroshell total angle of attack assuming \\
\hline$D_{V_{c}}$ & $=$ constrained vent diameter & & no wind \\
\hline$D_{V u}$ & $=$ unconstrained vent diameter & $\alpha_{P, T o t}$ & $=$ parachute total angle of attack \\
\hline$D_{0}$ & $=$ parachute nominal (reference) diameter & $\beta_{A S}$ & $=$ aeroshell angle of sideslip assuming no \\
\hline $\mathbf{F}_{\mathbf{P}}$ & $=$ total parachute force vector & & wind \\
\hline$F_{P}$ & $=$ total parachute force (magnitude), $\left|\mathbf{F}_{\mathbf{P}}\right|$ & $\gamma_{F P A}$ & $\begin{array}{l}=\text { flight path angle, positive above the } \\
\text { horizon }\end{array}$ \\
\hline$F_{P a 1}$ & $\begin{array}{l}=\text { parachute aerodynamic inflation force } \\
\text { at first peak } \\
=\text { component of the parachute force }\end{array}$ & $\Delta M$ & 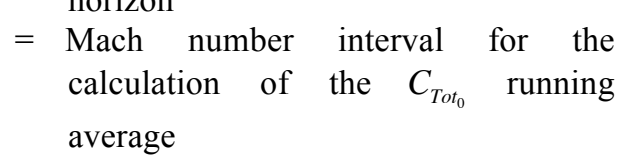 \\
\hline & $\begin{array}{l}\text { along the axis of symmetry of the } \\
\text { aeroshell, positive pointing upstream }\end{array}$ & $\Delta t_{M F}$ & $=$ time since mortar fire \\
\hline$H_{B}$ & $=$ band height & & $\begin{array}{l}=\text { aeroshell change in velocity induced } \\
\text { by mortar firing }\end{array}$ \\
\hline$H_{G}$ & $=$ gap height & $\theta_{P}$ & $=$ parachute pull angle \\
\hline$h$ & $=$ geodetic altitude & $\lambda_{g c}$ & $=$ constrained vent geometric porosity \\
\hline$L_{S}$ & $=$ suspension lines length & $\lambda_{g u}$ & $=$ unconstrained vent geometric porosity \\
\hline $\begin{array}{l}M \\
m_{P}\end{array}$ & $\begin{array}{l}=\text { Mach number } \\
=\text { parachute mass }\end{array}$ & $\Xi_{A S}$ & $=$ aeroshell total rotational acceleration \\
\hline $\begin{array}{l}m_{P} \\
N_{o o v}\end{array}$ & $\begin{array}{l}=\text { parachute mass } \\
=\text { number of gores (suspension lines) }\end{array}$ & $\rho_{\infty}$ & $\begin{array}{l}=\text { aeroshell total rotational acceleration } \\
=\text { atmospheric density }\end{array}$ \\
\hline$N_{g o r}$ & $\begin{array}{l}=\text { number of gores (suspension lines) } \\
r_{A S}=\text { aeroshell roll, pitch, and }\end{array}$ & $\Omega_{A S}$ & $\begin{array}{l}=\text { atmospheric density } \\
=\text { aeroshell total rotation rate }\end{array}$ \\
\hline
\end{tabular}

\section{Introduction}

$\mathrm{O}$ N August 6, 2012, the Mars Science Laboratory (MSL) entry, descent, and landing (EDL) system ${ }^{1}$ safely placed the Curiosity rover on the surface of Mars. A supersonically-deployed disk-gap-band (DGB) parachute was part of this EDL system. The parachute's performance has been reconstructed using data from the on-board inertial measurement unit (IMU), ground (terrestrial) measurements of the parachute system (e.g., dimensions), and various models. This paper's primary objective is to present the parachute performance reconstruction results.

For the design, development, and operation of the EDL system, an end-to-end simulation was created using the Program to Optimize Simulated Trajectories II (POST2). ${ }^{2,3}$ This simulation included numerous models related to the parachute system and its performance. ${ }^{4}$ This paper's secondary objective is to compare the parachute models and simulation's predictions against parachute performance reconstruction results.

In the companion paper, ${ }^{4}$ the POST2 simulation and parachute models are discussed in more detail. The descriptions of the MSL parachute system and its operation, as presented herein, are also included in reference 4. 


\section{Parachute Decelerator System}

\section{A. System Description}

The Mars Science Laboratory used a single, supersonically-deployed DGB parachute with a nominal diameter $\left(D_{0}\right)$ of $21.35 \mathrm{~m}$ (see figures 1 and 2). This DGB parachute was similar in geometric proportions to those used by the Viking missions to Mars, ${ }^{5}$ but 33 percent larger in nominal diameter, making it the largest parachute that has been deployed on Mars. Geometric details of the parachute are presented in table $1^{*}$ and figure 3 . The parachute's mass including deployment bag, canopy, suspension lines, suspension lines risers, single riser, confluence fitting, and triple bridle assembly was $57.5 \mathrm{~kg}$.

The disk was fabricated from two types of fabrics: a ripstop polyester of nominal $1.4 \mathrm{oz} / \mathrm{yd}^{2}$ areal weight manufactured to a Pioneer Aerospace specification on the crown, and a ripstop nylon of nominal $1.1 \mathrm{oz} / \mathrm{yd}^{2}$ areal weight per Parachute Industry Association specifications (PIA-C-7020B Type I for white nylon fabric, PIA-C-7020C, Type I for orange nylon fabric). All gores of the disk used a bias orientation. The various fabrics can be clearly seen in figure 2 . The band was fabricated from the same ripstop nylon fabrics described above using a block orientation. The suspension lines were fabricated from Technora T221 braided cord. All other textile structural elements were fabricated from Kevlar 29. The confluence fitting (located at the single riser-to-triple bridle confluence point) was fabricated using titanium TI-6AL-4V plate and A286 steel bolts.

Deployment was effected by a mortar ${ }^{6}$ with a muzzle velocity of approximately $39 \mathrm{~m} / \mathrm{s}$. The parachute was qualified to be deployed at Mach numbers up to 2.3, with a not-to-exceed peak parachute aerodynamic opening force (flight limit load) of $289 \mathrm{kN}(65,000 \mathrm{lb})$.

\section{B. Concept of Operation}

The MSL EDL concept of operation, starting from just prior to parachute deployment, is shown in figure 4. Nominal operation proceeds as follows

- During entry the MSL aeroshell is balanced such that its center of mass is offset from its axis of symmetry. This causes the aeroshell to trim at a total angle of attack of approximately $16^{\circ}$. This nonzero total angle of attack trim angle produces lift, which allows MSL's entry to be guided by banking the aeroshell. However, for parachute deployment, a near-zero total angle of attack is desired. Just prior to parachute deployment a series of six balance masses are ejected from the aeroshell at two-second intervals. The ejection of these balance masses brings the center of mass of the aeroshell to a location near its axis of symmetry, causing the aeroshell to fly at a total angle of attack of nominally less than five degrees - an acceptable value for supersonic parachute deployment. Deploying the parachute at a low total angle of attack also reduces the aeroshell dynamic motions by minimizing side forces on the aeroshell during inflation. Concurrently with the ejection of the balance masses, the reaction control system (RCS) rolls the aeroshell to the desired bank angle (for later radar operation purposes). The ejection of the balance masses and the rolling of the aeroshell is known as the Straighten Up and Fly Right (SUFR) maneuver. During the SUFR maneuver the RCS is used to damp pitch and yaw oscillations.

- After the SUFR maneuver is completed, the RCS is inhibited, the mortar is fired, and the parachute is deployed. Mortar fire is controlled by a navigated velocity magnitude trigger. ${ }^{8}$

- Parachute deployment and inflation occurs during a time interval of approximately $2 \mathrm{~s}$ after mortar fire.

- Ten seconds after mortar fire the RCS is re-enabled to damp aeroshell oscillations if necessary.

- Fifteen to thirty seconds after mortar fire the heatshield separation conditions are met. Heatshield separation is controlled by a "dot product" velocity trigger ${ }^{8}$ set to ensure an aeroshell Mach number of less than 0.8 at separation. The RCS is inhibited just prior to heatshield separation.

- Three seconds after heatshield separation the RCS is re-enabled to damp aeroshell oscillations if necessary.

- The aeroshell descends under parachute for 40 to $180 \mathrm{~s}$ until the descent stage separation conditions are met. Descent stage separation is commanded by an altitude/velocity trigger. ${ }^{8}$ The RCS is inhibited for a final time immediately preceding descent stage separation.

- The descent stage free falls unpowered for 1 second, followed by another $0.2 \mathrm{~s}$ for main landing engines (MLE) warm-up, and an additional $0.8 \mathrm{~s}$ for de-tumbling and turning into the initial attitude for powered flight. One of the powered descent stage's initial objectives is to perform a divert maneuver to avoid both short- and

\footnotetext{
*Al Witkowski of Pioneer Aerospace provided the as-built measured geometric data for the parachute presented in this paper. This contribution is gratefully acknowledged.
} 
long-term re-contact with the backshell and parachute. The rover is placed on the surface of Mars by the powered descent stage operating in the sky crane mode.

\section{Flight Data and Atmospheric Modeling}

\section{A. Descent Stage Inertial Measurement Unit Data and Derived Products}

The Descent Stage Inertial Measurement Unit (DIMU) was mounted on the descent stage. The acceleration and rotation rate data from the DIMU, and trajectory reconstruction products derived from it, were used for the parachute performance reconstruction. These data were available in three sets:

Set \#1: Unfiltered acceleration and rotation rate data at $200 \mathrm{~Hz}$.

Set \#2: Filtered acceleration and rotation rate data at $200 \mathrm{~Hz}$. A low pass filter was used to attenuate high frequency responses. This filter simulated the filtering performed on board the spacecraft in real time.

Set \#3: Filtered trajectory reconstruction data products at an average of $64 \mathrm{~Hz}$. These data products were obtained using a data set equivalent to Set \#2, mapped to an average of $64 \mathrm{~Hz} .^{\dagger}$ The time steps of Set \#3 data were either 0.015 or $0.020 \mathrm{~s}$. The long-term average of these time steps was $0.015625 \mathrm{~s}$ which implies an average frequency of $64 \mathrm{~Hz}$. This non-uniform time step size was required to map the Set \#2 data to Set \#3 data without interpolation.

All three of these data sets were used in the parachute performance reconstruction. Set \#1 data were used to determine the timing of events (e.g., mortar fire, heatshield separation) since these events could be clearly identified in this unfiltered data stream. However, the unfiltered data from Set \#1 was not suitable for obtaining peak accelerations, rotation rates, and rotational accelerations since it contained noise, apparently due to excited elastic structural modes (i.e., ringing), which compromised the accuracy of these peak values. Set \#2 data were used to obtain peak acceleration, rotation rates, and rotational accelerations. A comparison of the total sensed aeroshell acceleration at its center of mass for the first $2 \mathrm{~s}$ after mortar fire from Set \#1 and Set \#2 data are shown in figure 5 (using the Set \#1 time stamp). The noise in the Set \#1 data, as compared to the Set \#2, can be seen. A side effect of the filtering was the introduction of a slight lag in the filtered data as compared to the unfiltered data as can be seen in figure 5. Set \#3 data, the filtered trajectory reconstruction data products (e.g., altitude, inertial velocity, flight path angle, total angle of attack), were used for all other parachute performance reconstruction needs. An important fact to keep in mind regarding wind-relative quantities (e.g., airspeed, total angle of attack) in the present reconstruction is that it was assumed that the atmosphere was rotating with Mars, and there was no wind. This assumption compromised the accuracy of wind-relative quantities such as dynamic pressure and wind angles. The significance of this assumption increased as airspeed decreased during the parachute phase. Unfortunately it was not possible to accurately estimate the wind with the available information.

\section{B. Atmospheric Modeling}

Two mesoscale atmospheric models were created for the MSL EDL analyses. ${ }^{9}$ The Mars Mesoscale Model 5 (MMM5) model was created at Oregon State University. The Mars Regional Atmospheric Modeling System (MRAMS) model was created at the Southwest Research Institute. After landing these models were queried both spatially and temporally using the reconstructed trajectory flown by MSL, and adjusted to agree with the surface pressure (695 Pa) estimated from the Rover Environmental Monitoring System (REMS) on the Curiosity rover for the day and time of landing. ${ }^{\ddagger}$ The atmospheric profiles thus obtained were then used in the parachute performance reconstruction analyses. The density, $\rho_{\infty}$, and temperature, $T_{\infty}$, profiles for both of these models from just above the surface to just above the geodetic altitude, $h{ }^{\S}$ at mortar fire are shown in figure 6 . As can be seen from this figure, the models have almost identical density profiles, and just slightly different temperature profiles. At present these models are considered to be the best approximations of Mars' atmosphere on the day and time of landing in the altitude range relevant to the parachute. Both models are considered to be equally valid. Arbitrarily, the MMM5 model was selected for the parachute performance reconstruction results presented in the present paper. Nearly identical results were obtained with the MRAMS model. In the present reconstruction the wind is always assumed

\footnotetext{
${ }^{\dagger}$ The source data used to create Set \#3 was provided by Frederick Serricchio of the NASA Jet Propulsion Laboratory. His contribution is gratefully acknowledged.

$\$$ These adjustments and generation of the atmospheric profiles along the flown trajectory were performed by Alicia M. Dwyer Cianciolo of the NASA Langley Research Center. She made these atmospheric profiles available for use in the parachute reconstruction analyses. Her contribution is gratefully acknowledged.

$\S$ Altitude in this document is always expressed as a geodetic altitude. The assumed equatorial and polar radii of Mars are $3,396,190 \mathrm{~m}$ and 3,376,200 m, respectively.
} 
to be zero. The values of the gas constant and the ratio of specific heats used to calculate the speed of sound were $188.9221 \mathrm{~J} /(\mathrm{kg} \cdot \mathrm{K})$ and 1.335 , respectively.

\section{Reconstruction and Comparison to the Simulation}

\section{A. Mortar Fire State Vector}

Although not a parachute performance reconstruction result, the state vector at mortar fire is of great interest, since it affects the subsequent performance of the parachute. The key parameters of interest are Mach number, dynamic pressure, and wind angles (i.e., angle of attack, angle of sideslip, and total angle of attack). Values for these parameters are given in table 2. All reconstructed parameters are well within the expected range based on the final pre-flight Monte Carlo simulation results (8,000 trials).

\section{B. Events Timing and State}

Key events during the parachute operation are mortar fire, suspension lines stretch, first peak force, heatshield separation, and descent stage separation. The timing (from mortar fire), geodetic altitude, flight path angle, Mach number, and dynamic pressure for these events are given in table 3. Several observations can be made from these data. Deployment and inflation are of the infinite-mass type, as expected, with an approximately four percent reduction in the dynamic pressure from mortar fire to first peak force. The times from mortar fire to heatshield separation, and to descent stage separation, were within the expected bounds (see section II.B). The heatshield separation trigger performed as intended, commanding this event at a Mach number of 0.62 , well below the desired upper limit of 0.8 . Total time of parachute operation, from mortar fire to descent stage separation was $117 \mathrm{~s}$, during which MSL descended $10.4 \mathrm{~km}$.

The deployment model implemented in the POST2 simulation ${ }^{4}$ was set to yield a time from mortar fire to suspension lines stretch between 1.226 and $1.454 \mathrm{~s}$, with a uniform probability distribution between these two values. The reconstructed value for this time interval was $1.135 \mathrm{~s}$; this was $0.091 \mathrm{~s}$ lower than the model's lower bound. Similarly, the inflation model ${ }^{4}$ was set to yield a time from suspension lines stretch to first peak force between 0.636 and $0.812 \mathrm{~s}$, with a uniform probability distribution between these two values. Again, the reconstructed value for this time interval, $0.635 \mathrm{~s}$, was lower than the model's lower bound although just barely so $(0.001 \mathrm{~s})$ and within the reconstruction timing uncertainty of the event (given that data was collected at $200 \mathrm{~Hz}$ with a corresponding time steps of $0.005 \mathrm{~s}$ ). The simulation's predictions of important responses related to the performance of the EDL system was not sensitive to such small discrepancies in the deployment and inflation times.

\section{Mortar Performance}

Based on a mortar impulse of $2512 \mathrm{~N} \cdot \mathrm{s}$ (obtained from the Earth-based mortar qualification tests), and an estimated aeroshell mass of $2925 \mathrm{~kg}$ (at mortar fire), the predicted value of the aeroshell's change in velocity induced by mortar firing, $\Delta V_{M F}$, was $0.859 \mathrm{~m} / \mathrm{s}$. The reconstructed value of $\Delta V_{M F}$ was $0.743 \mathrm{~m} / \mathrm{s}$. Thus, the reconstructed value was 13.5 percent lower than the ground test value. This difference was not a cause for concern, however, given that the reconstructed value of $\Delta V_{M F}$ has uncertainty surrounding it due to noise in the DIMU signal that leads to its calculation, and the fact that the time from mortar fire to suspension lines stretch was shorter than expected indicating nominal mortar performance (see section IV.B).

\section{Deployment, Inflation, and Opening Forces}

The time history of the total parachute force (magnitude), $F_{P}$, acting on the aeroshell during the first $4 \mathrm{~s}$ after mortar fire is shown in figure 7. This force was calculated by determining the total force vector on the aeroshell, using the DIMU accelerometer data and the mass of the aeroshell, and subtracting the calculated aerodynamic force vector on the aeroshell. The total parachute force, $F_{P}$, is defined as the magnitude of this vector difference and thus it is always positive, regardless of orientation. The reconstructed Mach number, dynamic pressure, aeroshell angles of attack and sideslip, and the aeroshell aerodynamic database were used to calculate the aerodynamic force on the aeroshell. The DIMU and reconstruction data used were from Set \#3 (see section III.A). The initially large value of $F_{P}$ is the mortar recoil force, followed by snatch forces probably associated with arresting the sabot, triple bridle assembly, and triple bridle confluence fitting. Suspension lines stretch, and the subsequent small snatch force, can be clearly seen. Following suspension lines stretch the parachute inflated rapidly to a first peak force (which occurs at approximately the same time as first full inflation), followed by a single partial collapse cycle. In previous flight tests of DGB parachutes at supersonic speeds, large force oscillations after the first peak force had been observed at 
Mach numbers above 1.4 (see, for example, reference 10, describing the Viking Balloon Launched Decelerator Test (BLDT) AV-4). This is why the time for $M=1.4$ is identified in the total parachute force time history. Such force oscillations (often called area oscillations since they are often associated with changes in the projected area of the canopy) were of great concern to the MSL EDL team. However, except for the single cycle just after the first peak force, such force oscillations were absent from the MSL total parachute force time history. It is possible that the reason for the lack of such force oscillations was the longer parachute trailing distance of the MSL parachute $\left(10.32 D_{A S}\right.$ from the maximum aeroshell diameter to the skirt of the canopy, see figure 3 ) as compared to that of $\operatorname{Viking}^{10}\left(8.5 D_{A S}\right)$. The increased parachute trailing distance was incorporated into the MSL parachute with the purpose of diminishing these force oscillations by reducing the strength of the interaction between the aeroshell's wake and the canopy.

The aerodynamic portion of the total parachute inflation force at first peak, $F_{P a 1}$, was calculated from both the reconstruction, and as a set of 8,000 Monte Carlo simulation trials. For the reconstructed value $F_{P a 1}$ was estimated from the total parachute force, $F_{P}$, using the equation

$$
F_{P a 1}=\left(F_{P}+m_{P} a_{A S}\right)_{1}
$$

where $m_{P}$ is the mass of the parachute system not including the portion bookkept with the aeroshell (46.826 kg which includes the canopy, suspension lines, suspension lines risers, and half the single riser). ${ }^{4}$ The subscript "1" following the parenthesis on the right hand side of equation 1 means that $F_{P}$ and $a_{A S}$ are evaluated at the time of first peak force. Equation 1 is approximate because the total aeroshell sensed acceleration at its center of mass, $a_{A S}$, is used in the term $m_{P} a_{A S}$ to estimate the inertial force on the parachute. However, the term $m_{P} a_{A S}$ is a small portion of $F_{P a 1}$, so this approximation induces a negligibly small error in the calculation of $F_{P a 1}$. For the simulation calculation of $F_{P a 1}$ the equation

$$
F_{P a 1}=\left[q_{\infty} S_{0} C_{X}\left(C_{T}^{2}+C_{N}^{2}\right)^{\frac{1}{2}}\right]_{1}
$$

was used. In equation $2 C_{X}$ is the opening load factor, $C_{T}$ is the parachute's tangential force coefficient, and $C_{N}$ is the parachute's normal force coefficient in the total angle of attack plane (sometimes known as total or axisymmetry normal force coefficient). The reference area for both $C_{T}$ and $C_{N}$ is the parachute's nominal area, $S_{0}$. From previous test and mission data the preflight value of $C_{X}$ was conservatively estimated to be $1.407 .{ }^{4}$ The values of $C_{T}$ and $C_{N}$ are functions of the total angle of attack and Mach number, and are perturbed in the Monte Carlo trials. ${ }^{4}$ Note that $\left(C_{T}^{2}+C_{N}^{2}\right)^{\frac{1}{2}}$ is the total force coefficient of the parachute. The subscript "1" following the square brackets on the right hand side of equation 2 means that $q_{\infty}, C_{T}$, and $C_{N}$ are evaluated at the time and state of first peak force. To make the comparison between the reconstructed and simulation values relevant for evaluating the parachute models in the simulation, the simulation was re-executed in the following manner:

- The reconstructed state at mortar fire from data Set \#3, as described in section III.A, was used to initialize the simulation.

- The MMM5 atmospheric model (i.e., density and temperature profiles with respect to geodetic altitude) as described in section III.B was used. The density and temperature profiles were not perturbed as part of the Monte Carlo trials.

- Other quantities such as winds and parachute aerodynamic coefficients were perturbed as part of the Monte Carlo trials as they were in pre-flight simulations.

A histogram comparing the reconstructed and simulation Monte Carlo trials is shown in figure 8. The reconstructed value of $F_{P a 1}$ was $153.8 \mathrm{kN}$. The median and mean values from the Monte Carlo trials were 175.4 and $177.7 \mathrm{kN}$, respectively. Thus, the simulation median and mean values were 14.0 and 15.5 percent higher, respectively, than the reconstructed value. Only 8.8 percent of all simulation trials yielded a value of $F_{P a 1}$ lower than the reconstructed value." The higher median and mean values of $F_{P a 1}$ obtained from the simulation were expected, as the value of $C_{X}$ was intentionally selected to be conservative.

\footnotetext{
" The calculation used to determine the maximum likely parachute opening force for flight operations was different, and more conservative, than that shown in equation 2. See reference 4 for details.
} 


\section{E. Aeroshell Dynamics}

Aeroshell dynamics during the parachute phase were important to MSL because they could have affected heatshield separation, radar operation, descent stage separation, and structural loads on the aeroshell. The most important parameters to evaluate the aeroshell dynamics were the rotation rates, the total rotational acceleration, and the parachute pull angle. Each of these parameters were reconstructed and are discussed below.

The aeroshell total rotation rate, $\Omega_{A S}$, was calculated from the root-sum-square (RSS) of the roll, $p_{A S}$, pitch, $q_{A S}$, and yaw, $r_{A S}$, aeroshell body rotation rate components:

$$
\Omega_{A S}=\left(p_{A S}^{2}+q_{A S}^{2}+r_{A S}^{2}\right)^{\frac{1}{2}}
$$

This parameter was important to MSL because exceedingly high values could affect heatshield separation, radar operation, and descent stage separation. Figure 9 shows the total aeroshell rotation rate, $\Omega_{A S}$, vs. time since mortar fire, $\Delta t_{M F}$, from mortar fire to descent stage separation, with the timing of key events noted. The peak value of $\Omega_{A S}$ was $69.4 \mathrm{deg} / \mathrm{s}$, occurring about $5 \mathrm{~s}$ after mortar fire $(\sim 2.25 \mathrm{~s}$ after first peak force). After that time the aeroshell total rotation rate maximum amplitude decreased during the next $30 \mathrm{~s}$. After heatshield separation $\Omega_{A S}$ had only one peak that exceeds $30 \mathrm{deg} / \mathrm{s}$ and three peaks that exceed $20 \mathrm{deg} / \mathrm{s}$. During portions of the parachute phase the RCS was enabled to damp the rotation rates $p_{A S}, q_{A S}$, or $r_{A S}$ if needed. The time intervals during which RCS damping was enabled are shown in figure 9 (see also section III.B). There are two such intervals: after the initial deployment and inflation transient but prior to heatshield separation, and after heatshield separation to just prior to descent stage separation. In table 4 the deadband values for RCS firing are shown for the two RCS-enabled time intervals, together with the reconstruction values of the rotation rates. As can be determined from these data, the actual rotation rates were well within the RCS deadband for both time intervals. Thus, the RCS did not fire to damp the rotation rates.

To evaluate the validity of the simulation with respect to the total rotation rate, $\Omega_{A S}$, its maximum value within one-second bins starting at mortar fire, $\operatorname{Max}\left(\Omega_{A S}\right)$ within $\left(\Delta t_{M F}, \Delta t_{M F}+1 \mathrm{~s}\right]$ for $\Delta t_{M F}=0,1,2 \mathrm{~s}, \ldots$, were recorded. This was done for both the reconstructed values and the results of the 8,000-trial Monte Carlo simulation initialized at mortar fire as described earlier (see section IV.D). For the Monte Carlo simulation results these data were then used to determine the percentiles for each one-second bin. The results of these calculations are presented in figure 10 for the first $40 \mathrm{~s}$ following mortar fire. For most of the time interval being considered the reconstruction values were within the 10 to $90 \%$-tile interval. Two points about $5 \mathrm{~s}$ after mortar fire exceed the $90 \%$-tile level, but did not exceed the $99 \%$-tile level. The trend was for the reconstructed values to be lower than the $50 \%$-tile level after heatshield separation (at $\Delta t_{M F} \approx 20 \mathrm{~s}$ ). The data shown in figure 10 indicated that the simulation did a good job of capturing the total oscillation rate of the aeroshell.

The aeroshell total rotational acceleration, $\Xi_{A S}$, was calculated from the RSS of the roll, $\dot{p}_{A S}$, pitch, $\dot{q}_{A S}$, and yaw, $\dot{r}_{A S}$, aeroshell body rotational acceleration rate components:

$$
\Xi_{A S}=\left(\dot{p}_{A S}^{2}+\dot{q}_{A S}^{2}+\dot{r}_{A S}^{2}\right)^{\frac{1}{2}}
$$

This parameter was important to MSL due to structural loads considerations. An MSL requirement specified that the aeroshell total rotational acceleration should not exceed $2,126 \mathrm{deg} / \mathrm{s}^{2}\left(37.1 \mathrm{rad} / \mathrm{s}^{2}\right)$. Figure 11 shows the total aeroshell rotation rate, $\Xi_{A S}$, vs. time since mortar fire, $\Delta t_{M F}$, from mortar fire to descent stage separation. The peak aeroshell total rotational acceleration was $625 \mathrm{deg} / \mathrm{s}^{2}\left(21.8 \mathrm{rad} / \mathrm{s}^{2}\right)$, well below the MSL requirement, and occurred about $2.3 \mathrm{~s}$ after mortar fire $(\sim 0.58 \mathrm{~s}$ after first peak force). After that time the aeroshell total rotational acceleration maximum amplitude decreased during the next $30 \mathrm{~s}$.

In an analysis similar to that performed for $\Omega_{A S}$, the maximum values of $\Xi_{A S}$ within one-second bins starting at mortar fire were recorded. This was done for both the reconstructed values, and the results of the 8,000-trial Monte Carlo simulation initialized at mortar fire. For the Monte Carlo simulation results, these data were then used to determine the percentiles for each one-second bin. The results of these calculations are presented in figure 12 for the first $40 \mathrm{~s}$ following mortar fire. Except for a few points, the reconstructed values are within the 10 to $90 \%$-tile interval. The data shown in figure 12 indicates that the simulation did a good job of capturing the aeroshell total rotational rate acceleration.

The parachute pull angle, $\theta_{P}$, is the angle between the total parachute force vector, $\mathbf{F}_{\mathbf{P}}$, and the negative axis of symmetry of the aeroshell. It is calculated from: 


$$
\theta_{P}=\arccos \left(-F_{P_{x}} /\left|\mathbf{F}_{\mathbf{P}}\right|\right)
$$

where $F_{P_{x}}$ is the component of the parachute force along the axis of symmetry of the aeroshell, positive pointing upstream. The parachute pull angle was important to MSL because it affected both aeroshell dynamics and structural loads. In figure 13 the time history of $\theta_{P}$ is shown from shortly after mortar fire to descent stage separation. The data plotted in this figure starts after suspension lines stretch, once the parachute force magnitude along the axis of symmetry exceeds twice the equivalent value for the aeroshell at $\Delta t_{M F} \approx 1.6 \mathrm{~s}$. At earlier times the uncertainties associated with the reconstructed $\mathbf{F}_{\mathbf{P}}$ yielded unreliable values of $\theta_{P}$. The maximum parachute pull angle of 9.2 degrees occurred about $3 \mathrm{~s}$ after the first peak force. For $\Delta t_{M F}>25 \mathrm{~s}$, after the heatshield separation transient passed, and up to descent stage separation, the parachute pull angle was oscillatory, with values of approximately $2 \pm 2$ degrees; rarely did the parachute pull angle exceed four degrees in this time interval. The relatively small values of $\theta_{P}$ (especially after heatshield separation) indicate that the aeroshell and parachute were moving almost as if they were a single body.

In analysis similar to that performed and described earlier for $\Omega_{A S}$ and $\Xi_{A S}$, the maximum values of $\theta_{P}$ within one-second bins were recorded, starting at mortar fire for both the reconstruction and for 8,000 Monte Carlo simulation trials. These results are shown in figure 14 for the first $40 \mathrm{~s}$ following mortar fire. Because of the issue mentioned earlier related to the uncertainty associated with $\mathbf{F}_{\mathbf{P}}$, bins encompassing deployment and the initial inflation are not shown in this graph - the first bin shown is for $2 \mathrm{~s}<\Delta t_{M F} \leq 3 \mathrm{~s}$. Except for two points, the reconstructed values are within the 10 to $90 \%$-tile interval. After the heatshield separation transient passed $\left(\Delta t_{M F}>25 \mathrm{~s}\right)$ the reconstruction results were below the 50\%-tile Monte Carlo simulation results. The data in figure 14 indicates that the simulation did an acceptable job of capturing the parachute pull angle.

\section{F. Parachute Total Force and Drag Coefficients}

A total parachute force coefficient, $C_{\text {Tot }_{0}}$, was calculated from the total parachute force, $F_{P}$, using the equation

$$
C_{T o t_{0}}=\frac{F_{P}}{q_{\infty} S_{0}}
$$

Figure 15 show the reconstructed value of $C_{T t_{0}}$ vs. time since mortar fire from first peak force at $\Delta t_{M F}=1.8 \mathrm{~s}$ and $M=1.70$ to descent stage separation at $\Delta t_{M F}=116.8 \mathrm{~s}$ and $M=0.32$. The oscillations were due to transients after discrete events (e.g., first peak force, area oscillations, heatshield separation), and response to state variables such as the parachute total angle of attack and rotation rates (including the effects of atmospheric shear and turbulence). The total parachute force coefficient is approximately related to the parachute drag coefficient, $C_{D_{0}}$, through the parachute total angle of attack, $\alpha_{P, \text { Tot }}$ :

$$
C_{D_{0}} \approx C_{T_{0 t_{0}}} \cos \alpha_{P, T o t}
$$

The approximation resides in the assumption that $C_{T t_{0}} \approx C_{T}$; this is only strictly true if $C_{N}=0$. However since in general $C_{N} \ll C_{T}$ this approximation is adequate for the present purpose. For small values of $\alpha_{P, \text { Tot }}, C_{T t_{0}}$ is an approximation of $C_{D_{0}}$ (for example if $\alpha_{P, T o t}=18^{\circ}, C_{D_{0}}=0.95 C_{T t_{0}}$ ). Notice that $C_{T t_{0}}$ is always greater than or equal to $C_{D_{0}}$. For MSL a pre-flight parachute drag coefficient model was created. ${ }^{4}$ This parachute drag coefficient model was a function of Mach number only. Three levels were defined for this parachute drag coefficient model: a lower (Low) bound, a nominal, and an upper (High) bound. These levels are denoted by the symbols $\left(C_{D_{0}}\right)_{\text {Low }}$, $\left(C_{D_{0}}\right)_{\text {Nominal }},\left(C_{D_{0}}\right)_{\text {High }}$. This model is shown by a solid (Nominal) and dashed (Low and High) lines in figure 16. With further processing of the parachute total force coefficient reconstruction results a useful comparison can be made against the parachute drag coefficient model. In figure 16 Mach number averaged values of the reconstructed $C_{\text {Tot }_{0}}$ are shown. This averaging was performed over all data in windows of width $\Delta M=0.03$, or in other words over the intervals $[M-0.015 \leq M \leq M+0.015]$. Averaging $C_{T t_{0}}$ in this manner greatly reduced the high frequency

\footnotetext{
${ }^{\#}$ Note that $F_{P}=\left|\mathbf{F}_{\mathbf{P}}\right|$.
} 
oscillatory behavior seen in figure 15. Data for $\Delta t_{M F}<2.25 \mathrm{~s}(M>1.62)$, for $C_{T_{0 t}}$ has not been plotted in figure 16 because it contains inflation transient oscillations not relevant to the present discussion (see figure 7). Keeping in mind the previous remarks regarding the relationship between $C_{T_{0 t}}$ and $C_{D_{0}}$, examination of the data in figure 16 indicates that the parachute drag coefficient model (including the lower and upper bounds) was an adequate representation of the actual drag coefficient. The average value of $C_{\text {Tot }_{0}}$ using all reconstruction data for $M<0.6$ (i.e., after heatshield separation) was 0.624 , which was close to the value of $\left(C_{D_{0}}\right)_{\text {Nominal }}, 0.615$, in this same Mach number range.

\section{Concluding Remarks}

The MSL EDL reconstruction indicates that the parachute system performance on Mars was nominal. Deployment and inflation occurred slightly faster than modeled in the pre-flight simulation. The first peak parachute force was well within the limits of the parachute strength. The median value of the first peak parachute force obtained from Monte Carlo trials of the simulation over-predicted this parameter (as was intended). Aeroshell dynamics (e.g., rotation rates, total rotational acceleration) were well within the bounds for successful operation of the EDL system. The EDL simulation was successful in predicting the aeroshell dynamics within reasonable bounds. Reconstruction of the total parachute force coefficient indicates that the parachute drag coefficient model created prior to flight is an adequate representation of the parachute's drag coefficient. The reconstructed parachute performance results will be useful to improve parachute models and EDL simulations for future missions.

\section{Acknowledgements}

A number of groups and individuals provided data that made the reconstruction described herein possible. The authors thank the MSL Guidance Navigation and Control Team for the DIMU data and trajectory reconstruction, and the MSL Council of Atmospheres for the atmospheric models. The Mars Science Laboratory mission is directed by the Jet Propulsion Laboratory, California Institute of Technology, under contract to NASA.

\section{References}

${ }^{1}$ Prakash, R., et al., "Mars Science Laboratory Entry, Descent, and Landing System Overview," IEEE Aerospace Conference, Big Sky, MT, March 1-8, 2008.

${ }^{2}$ Striepe, S. A., Way, D. W., Dwyer, A. M., and Balaram, J., "Mars Science Laboratory Simulations for Entry, Descent, and Landing," Journal of Spacecraft and Rockets, Vol. 43, No. 2, 2006, pp. 311-323.

${ }^{3}$ Way, D. W., Davis, J. L., and Shidner, J. D., "Assessment of the Mars Science Laboratory Entry, Descent, and Landing Simulation," 23 ${ }^{\text {rd }}$ AAS/AIAA Space Flight Mechanics Meeting (AAS paper 13-420), Kauai, HI, February 10-14, 2013.

${ }^{4}$ Cruz, J. R., et al., "Parachute Models Used in the Mars Science Laboratory Entry, Descent, and Landing Simulation," $22^{\text {nd }}$ AIAA Aerodynamic Decelerator Systems Technology Conference and Seminar (AIAA Paper 2013-1276), Daytona Beach, FL, March 25-28, 2013.

${ }^{5}$ Anon., "Viking Lander “As Built” Performance Capabilities,” Martin Marietta Corp. Report, NASA Contract NAS1-9000, 1976.

${ }^{6}$ Rowan, J., Moran, J., and Adams, D. S., "Development and Qualification of the Mars Science Laboratory Mortar Deployment System," $20^{\text {th }}$ AIAA Aerodynamic Decelerator Systems Technology Conference and Seminar (AIAA Paper 2009-2916), Seattle, WA, May 4-7, 2009.

${ }^{7}$ Adams, D. S. and Rivellini, T. P., "Mars Science Laboratory's Parachute Qualification Approach," $20^{\text {th }}$ AIAA Aerodynamic Decelerator Systems Technology Conference and Seminar (AIAA Paper 2009-2913), Seattle, WA, May 4-7, 2009.

${ }^{8}$ Kipp, D., San Martin, M., Essmiller, J., and Way, D., "Mars Science Laboratory Entry, Descent, and Landing Triggers," IEEE Aerospace Conference (IEEEAC Paper 1145 Version 2), Big Sky, MT, March 3-10, 2007.

${ }^{9}$ Vasavada, A. R., et al., "Assessment of Environments for Mars Science Laboratory Entry, Descent, and Surface Operations," Space Science Reviews, Vol. 170, Issue 1-4, Sept. 2012, pp. 793-835.

${ }^{10}$ Dickinson, D., Schlemmer, J., Hicks, F., Michel, F., and Moog, R. D., "Balloon Launched Decelerator Test Program, Post-Flight Test Report, BLDT Vehicle AV-4,”NASA CR-112179, 1972. 
Table 1. As-built key geometric parameters of the MSL parachute.

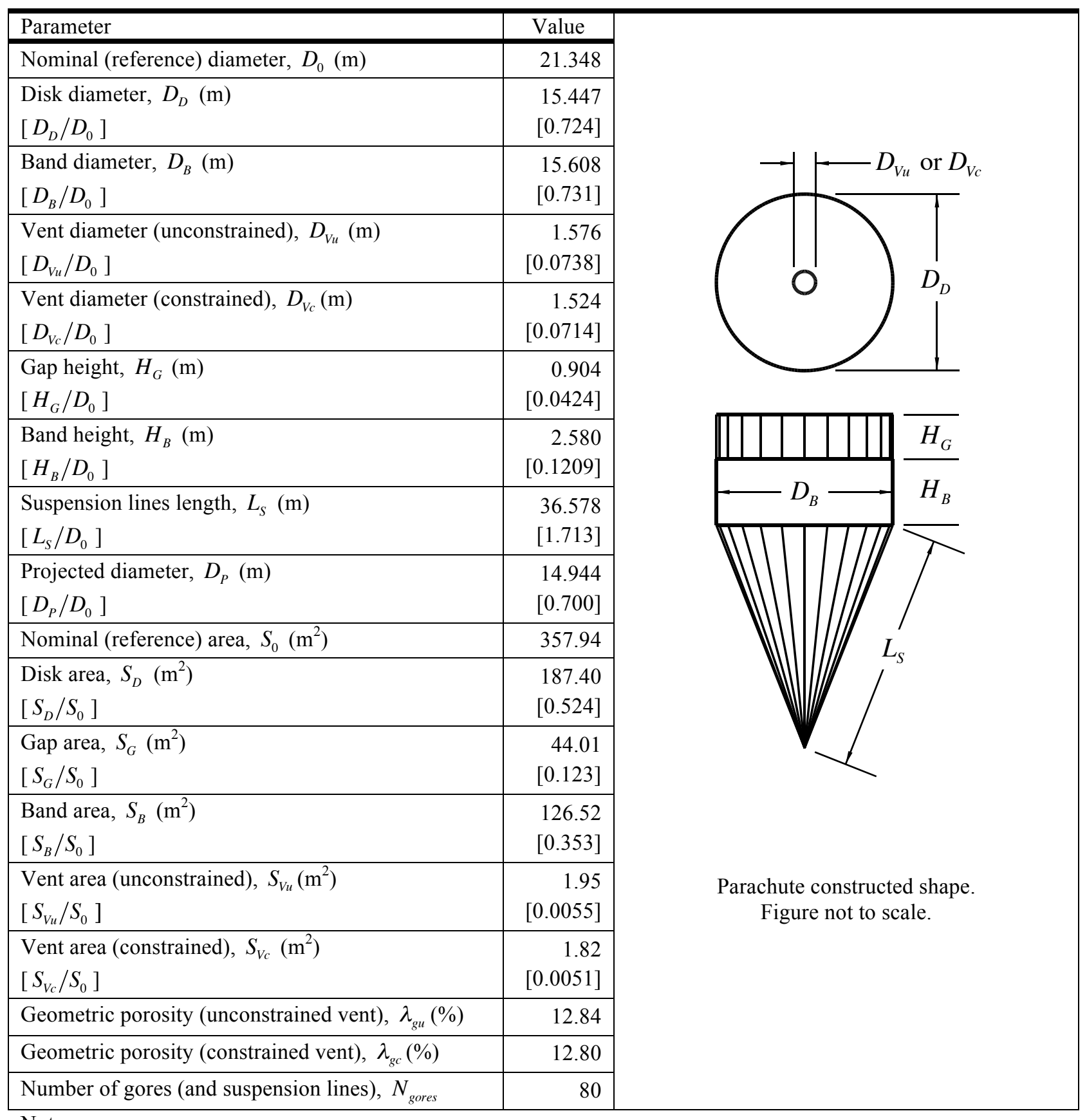

Notes:

- Most of the data in this table was provided by Al Witkowski of Pioneer Aerospace.

- Constraint on vent diameter is due to the vent cords.

- As defined here the suspension lines length is the distance from the parachute skirt to the imaginary confluence point the physical suspension lines would reach if they were extended. In actual construction the suspension lines length as defined here consists of both physical suspension lines and risers that collect sets of suspension lines into fewer load paths.

- The projected diameter $D_{P}$ and the ratio $D_{P} / D_{0}$ are estimates. 
Table 2. Flight reconstructed and pre-flight simulation state vector at mortar fire.

\begin{tabular}{|l|c|c|}
\hline Parameter & $\begin{array}{c}\text { Reconstructed } \\
\text { Value }\end{array}$ & $\begin{array}{c}\text { Simulation Monte Carlo } \\
\text { Results } \\
{[2.5 \% \text {-tile, median, 97.5\%-tile] }}\end{array}$ \\
\hline Mach number, $M$ & 1.75 & {$[1.56,1.69,1.84]$} \\
\hline Dynamic pressure, $q_{\infty}(\mathrm{Pa})$ & 493.6 & {$[441.4,494.1,553.7]$} \\
\hline Aeroshell angle of attack, $\alpha_{A S}(\mathrm{deg})$ & 2.76 & {$[-2.97,0.56,4.38]$} \\
\hline Aeroshell angle of sideslip, $\beta_{A S}(\mathrm{deg})$ & -2.18 & {$[-2.27,0.88,3.80]$} \\
\hline Aeroshell total angle of attack, $\alpha_{A S, T o t}(\mathrm{deg})$ & 3.52 & {$[0.44,2.24,5.01]$} \\
\hline
\end{tabular}

Notes:

- The reconstructed wind angles, $\alpha_{A S}, \beta_{A S}$, and $\alpha_{A S, T o t}$ are calculated assuming no wind.

- The simulation Monte Carlo results are for the final pre-flight run with 8,000 trials.

Table 3. Key events timing and states.

\begin{tabular}{|l|r|c|c|c|c|}
\hline Event & \multicolumn{1}{|c|}{$\Delta t_{M F}(\mathrm{~s})$} & $h(\mathrm{~m})$ & $\gamma_{F P A}(\mathrm{deg})$ & $M$ & $q_{\infty}(\mathrm{Pa})$ \\
\hline Mortar fire & 0.000 & 7,118 & -22.4 & 1.752 & 493.6 \\
\hline Suspension lines stretch & 1.135 & 6,938 & -22.9 & 1.737 & 493.2 \\
\hline First peak force & 1.770 & 6,837 & -23.2 & 1.695 & 474.0 \\
\hline Heatshield separation & 19.745 & 4,934 & -37.0 & 0.618 & 74.9 \\
\hline Descent stage separation & 116.633 & $-3,259$ & -85.5 & 0.324 & 42.2 \\
\hline
\end{tabular}

Notes:

- By definition $\Delta t_{M F}$ is zero at mortar fire.

- The timing of events were determined by the first point at which the event was evident in the Set \#1 data (see section III.A).

- The states were determined by the first point at which the event was evident in the Set \#3 data (see section III.A).

- The flight path angle, $\gamma_{F P A}$, is defined as positive above the horizon.

Table 4. Maximum rotation rates.

\begin{tabular}{|l|c|c|c|c|c|}
\cline { 2 - 5 } \multicolumn{1}{c|}{} & \multicolumn{2}{c|}{ RCS Deadband } & \multicolumn{3}{c|}{ Reconstructed Values } \\
\cline { 2 - 5 } & $\begin{array}{c}\text { RCS-Enabled } \\
\text { Time Interval } \\
\text { Prior to } \\
\text { Heatshield } \\
\text { Separation }\end{array}$ & $\begin{array}{c}\text { RCS-Enabled } \\
\text { Time Interval } \\
\text { After Heatshield } \\
\text { Separation }\end{array}$ & $\begin{array}{c}\text { RCS-Enabled } \\
\text { Time Interval } \\
\text { Prior to } \\
\text { Heatshield } \\
\text { Separation }\end{array}$ & $\begin{array}{c}\text { RCS-Enabled } \\
\text { Time Interval } \\
\text { After Heatshield } \\
\text { Separation }\end{array}$ & $\begin{array}{c}\text { Complete } \\
\text { Parachute Phase } \\
\text { - Mortar Fire to } \\
\text { Descent Stage } \\
\text { Separation }\end{array}$ \\
\hline$\left|p_{A S}\right|_{\text {Max }}(\mathrm{deg} / \mathrm{s})$ & 10.0 & 10.0 & 2.1 & 2.7 & 2.9 \\
\hline$\left|q_{A S}\right|_{\text {Max }}(\mathrm{deg} / \mathrm{s})$ & 80.0 & 50.0 & 25.5 & 23.0 & 64.3 \\
\hline$\left|r_{A S}\right|_{\text {Max }}(\mathrm{deg} / \mathrm{s})$ & 80.0 & 50.0 & 32.0 & 21.1 & 40.2 \\
\hline$\left(\Omega_{A S}\right)_{\operatorname{Max}}(\mathrm{deg} / \mathrm{s})$ & Not applicable & Not applicable & 38.0 & 31.0 & 69.4 \\
\hline
\end{tabular}




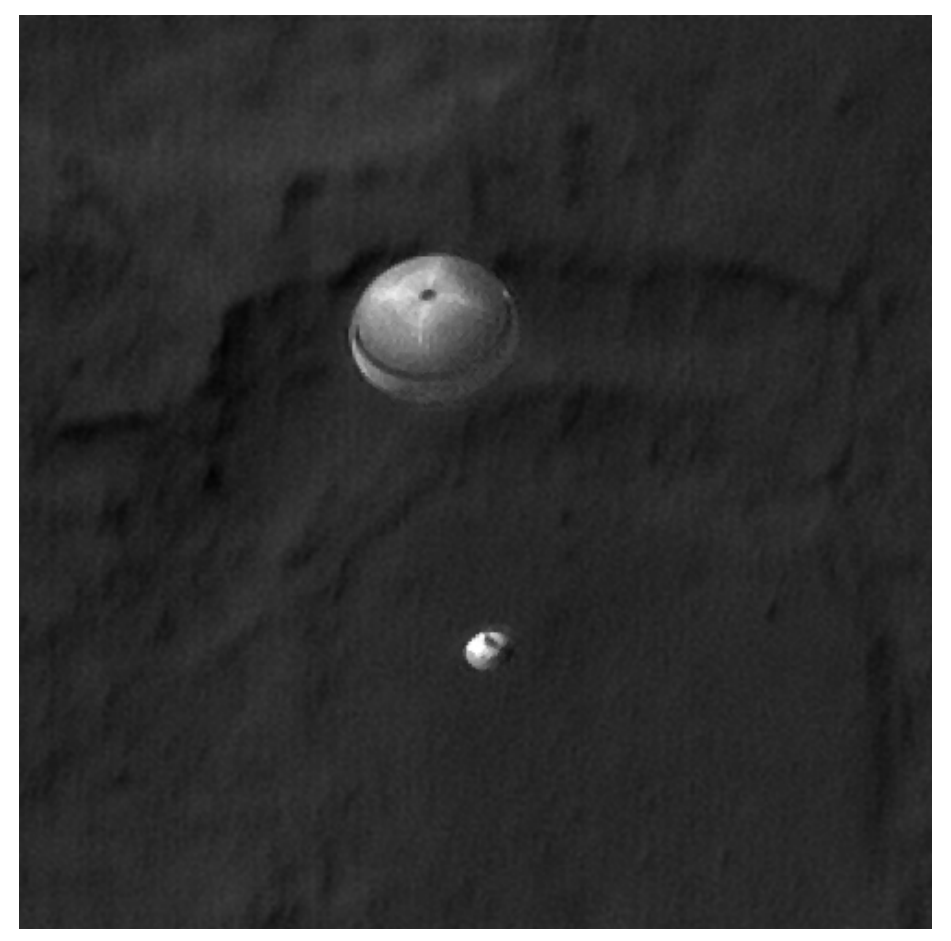

Figure 1. MSL parachute in operation on Mars photographed by the HiRISE camera on the Mars Reconnaissance Orbiter. Image credit: NASA / JPL-Caltech / Univ. of Arizona.

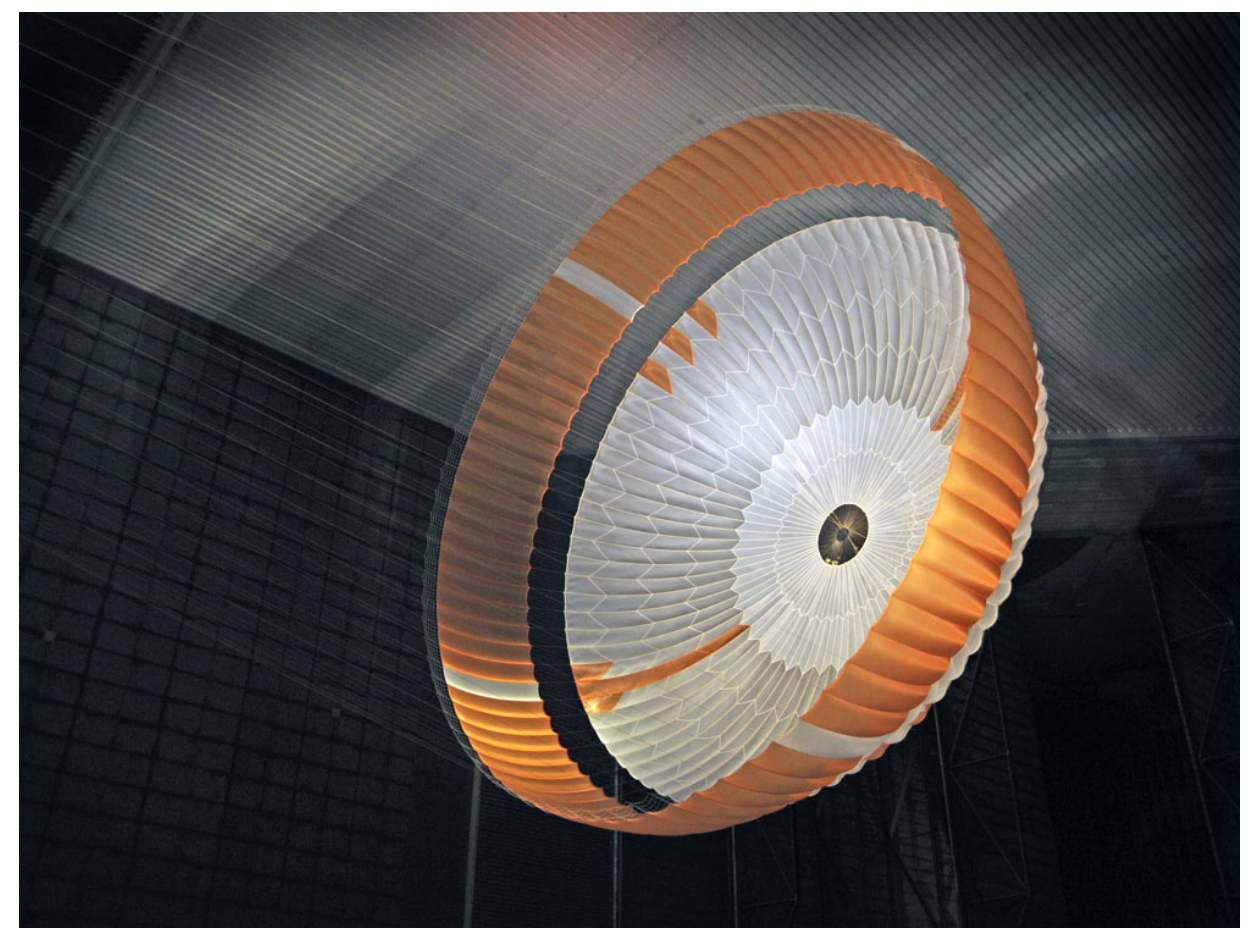

Figure 2. MSL parachute being tested at the National Full-Scale Aerodynamics Complex wind tunnel located at the NASA Ames Research Center in Moffett Field, California. The anti-inversion netting seen attached to the skirt of the canopy was only present for subsonic testing and was not present on the parachute flown on Mars. Image credit: NASA / JPL-Caltech. 

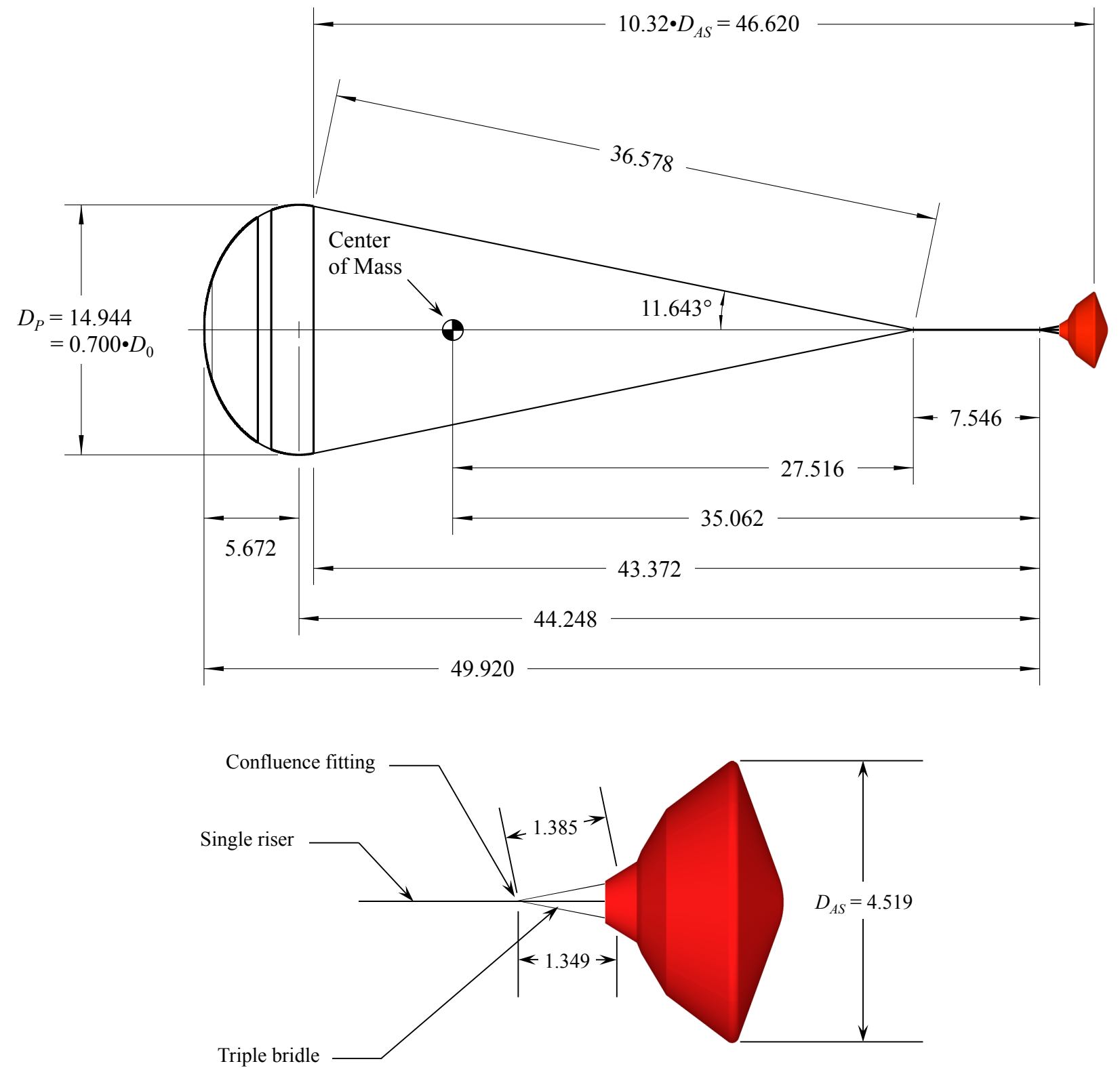

Figure 3. Parachute system dimensions. All linear dimensions in meters. Note that the triple bridle legs attach to the aeroshell inside its outer mold line. Aeroshell graphic by Karl T. Edquist, NASA Langley Research Center. 


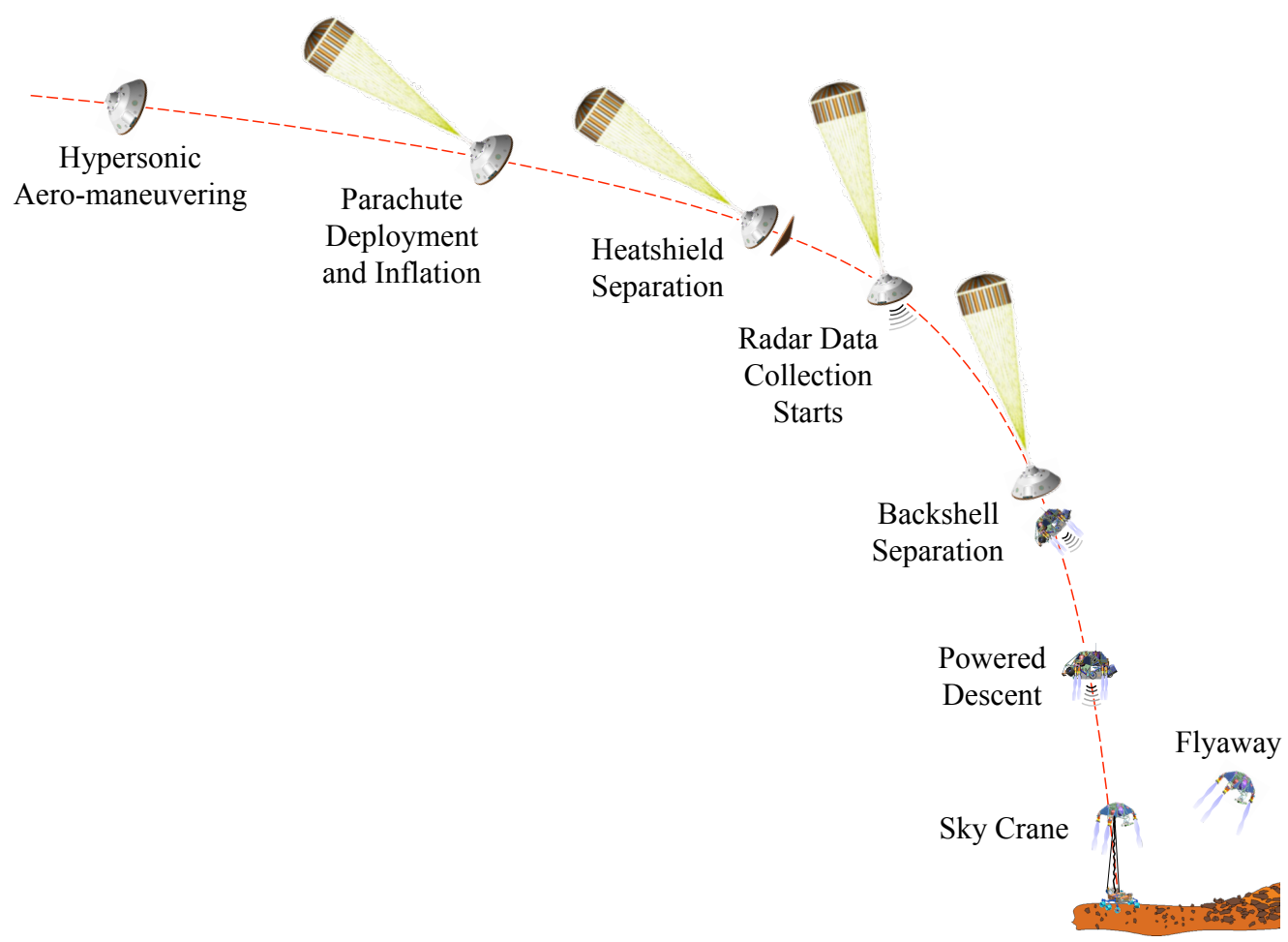

Figure 4. MSL EDL concept of operation from just prior to parachute deployment. Graphics source: JPL-Caltech.

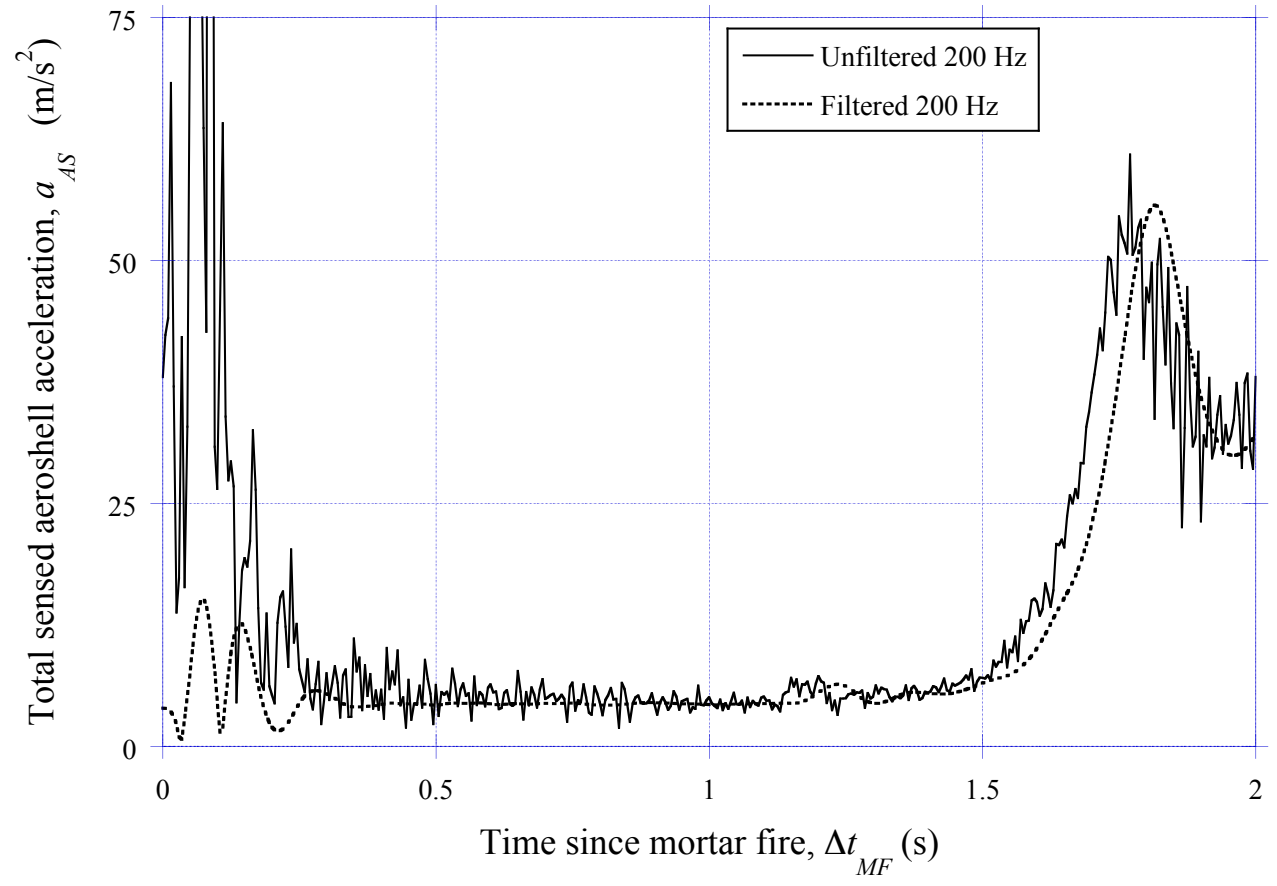

Figure 5. Comparison between the unfiltered (Set \#1) and filtered (Set \#2) $200 \mathrm{~Hz}$ DIMU data. The time stamp used is that for the Set \#1 data. The total sensed aeroshell acceleration at its center of mass, $a_{A S}$, is defined as the root-sum-square (RSS) of the body coordinate system sensed acceleration components. Thus, $a_{A S}$ is always positive. 


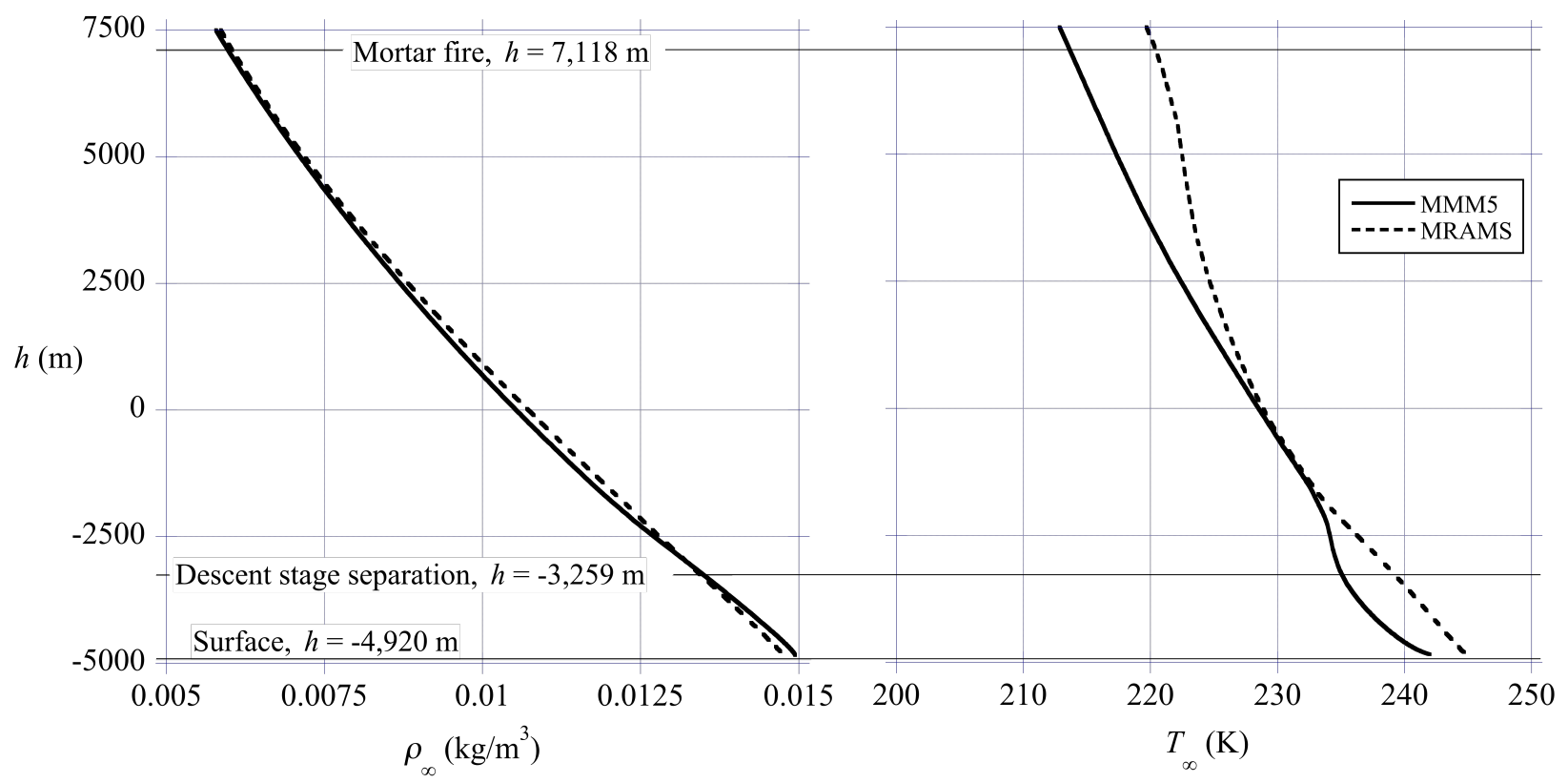

Figure 6. Comparison of the MM5 and MRAMS atmospheric models.

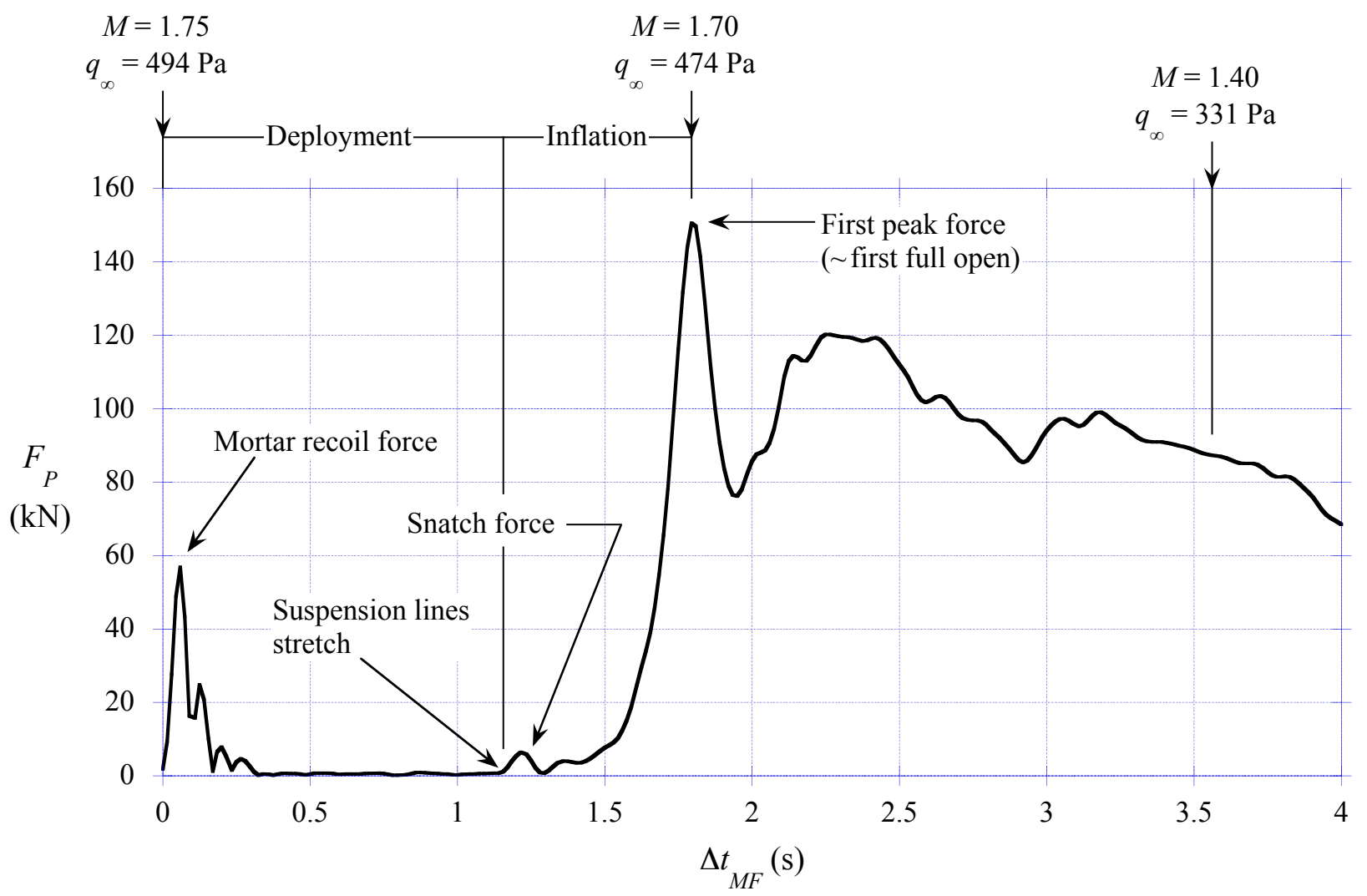

Figure 7. Total parachute force time history for the first $4 \mathrm{~s}$ after mortar fire. 


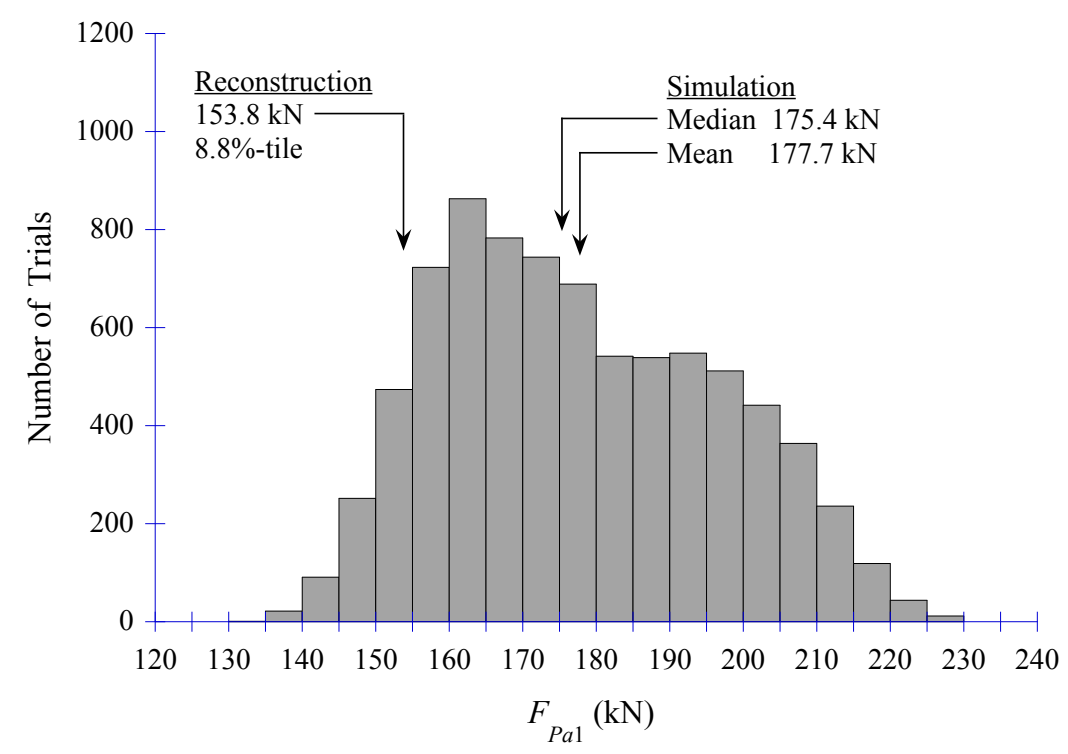

Figure 8. Histogram comparing the parachute aerodynamic inflation force at first peak obtained from the reconstruction, against the corresponding simulation Monte Carlo results (8,000 trials) using flight initial conditions.

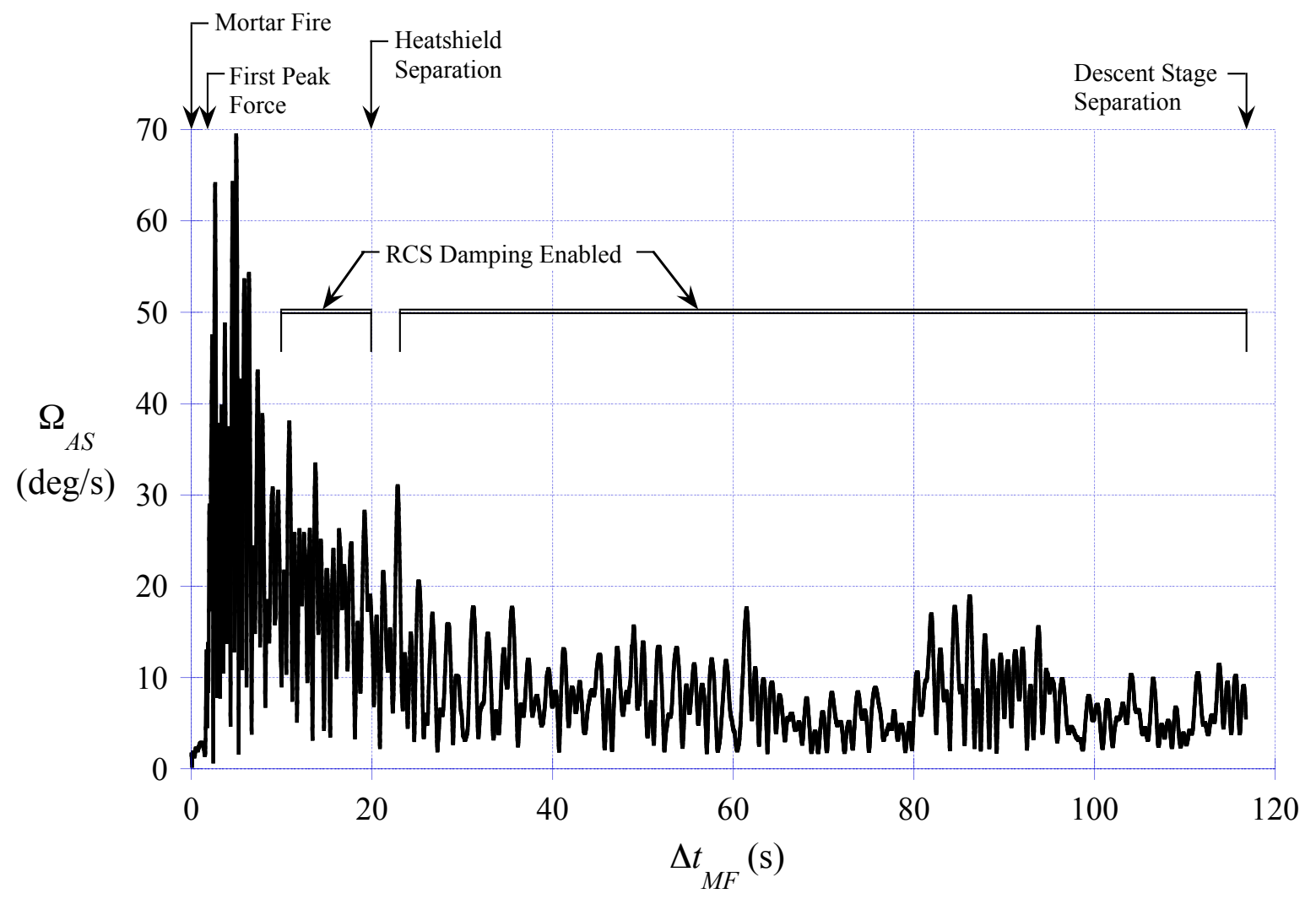

Figure 9. Aeroshell total rotation rate, $\Omega_{A S}$, vs. time since mortar fire, $\Delta t_{M F}$, during the parachute phase. Key events are marked. The horizontal double lines identify the time intervals during which RCS damping was enabled; however, they are not the RCS deadband values. See table 4 for the values of these RCS deadbands. 


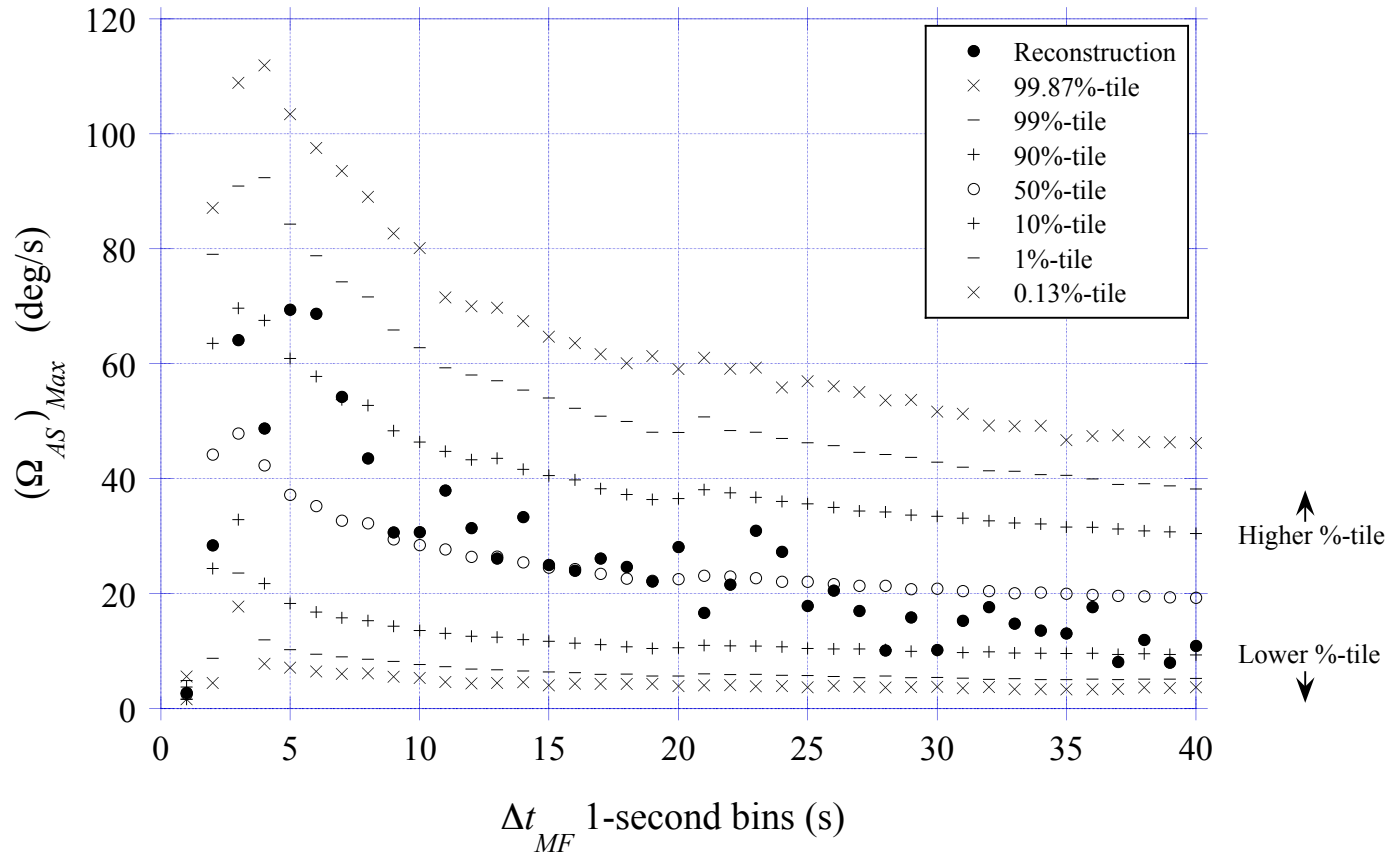

Figure 10. Maximum value of $\Omega_{A S}$ within one second bins, starting at mortar fire. The symbols are placed at the end of the one-second bins. The solid circles denote the reconstruction values. The other symbols show the results from an 8,000-trial Monte Carlo simulation runs, presented in terms of percentiles.

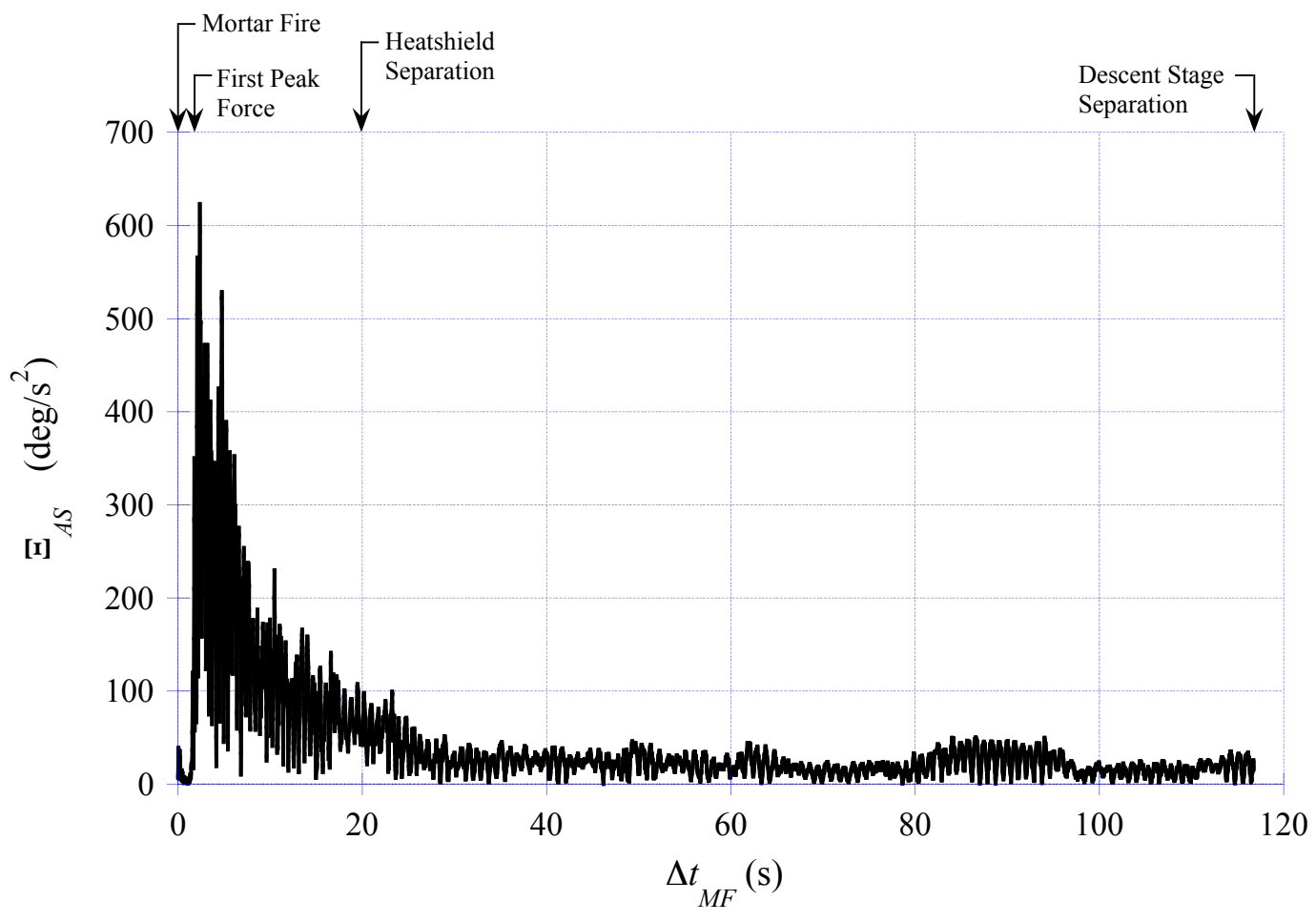

Figure 11. Aeroshell total rotational acceleration, $\Xi_{A S}$, vs. time since mortar fire, $\Delta t_{M F}$, during the parachute phase. Key events are marked. 


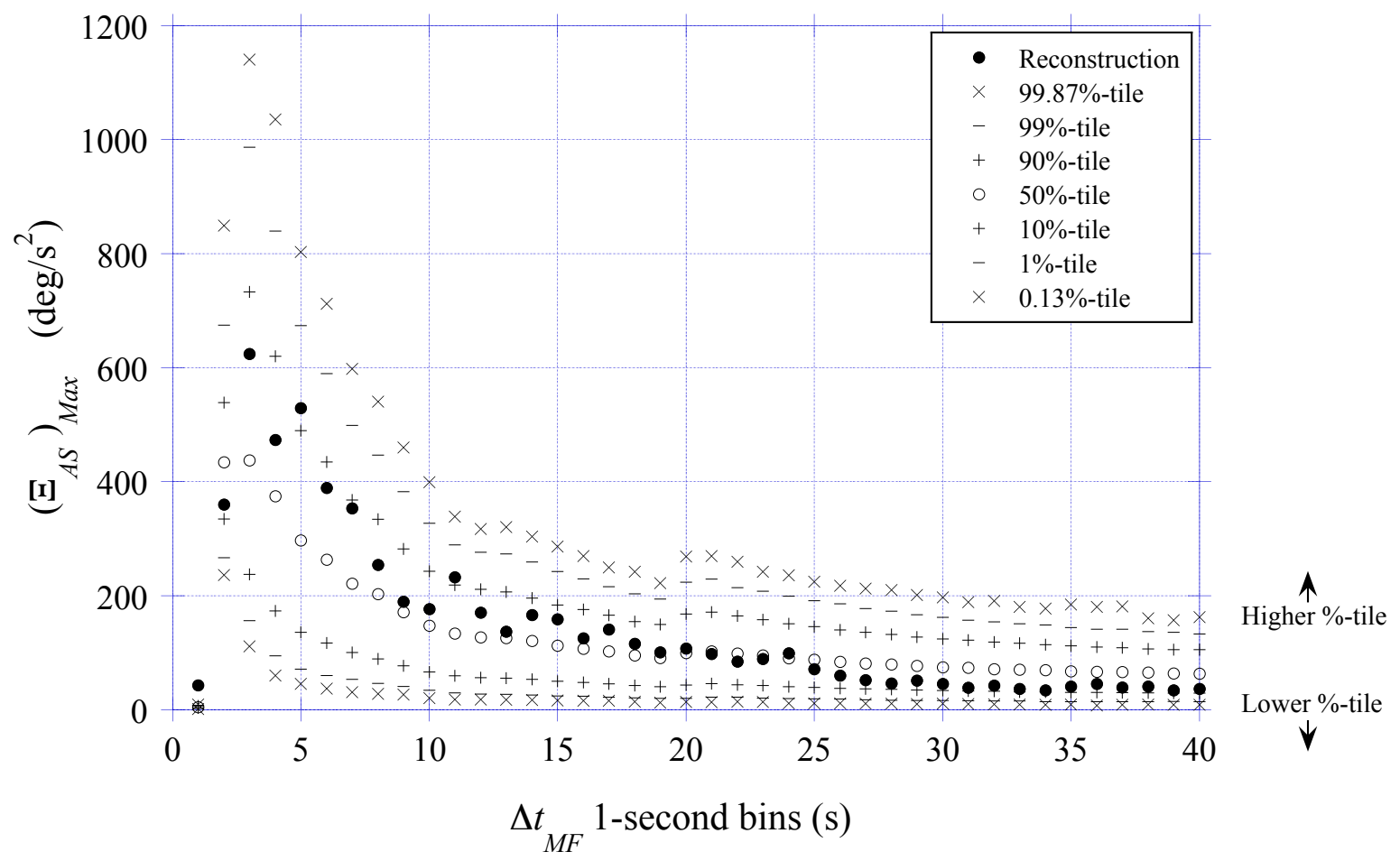

Figure 12. Maximum value of $\Xi_{A S}$ within one second bins, starting at mortar fire. The symbols are placed at the end of the one-second bins. The solid circles denote the reconstruction values. The other symbols show the results from an 8,000-trial Monte Carlo simulation run, presented in terms of percentiles.

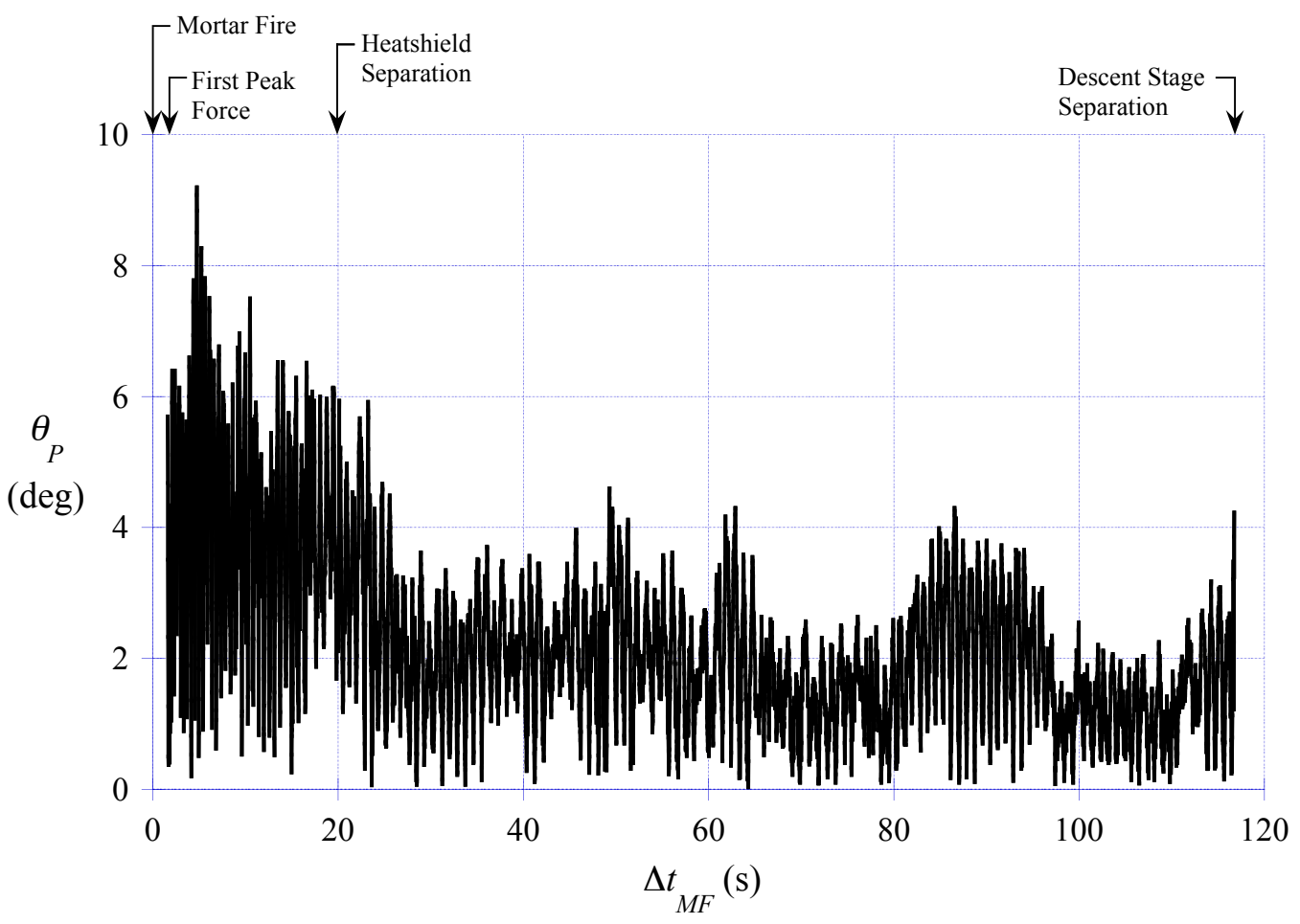

Figure 13. Parachute pull angle, $\theta_{P}$, vs. time since mortar fire, $\Delta t_{M F}$, during the parachute phase for $\Delta t_{M F}>1.6 \mathrm{~s}$. 


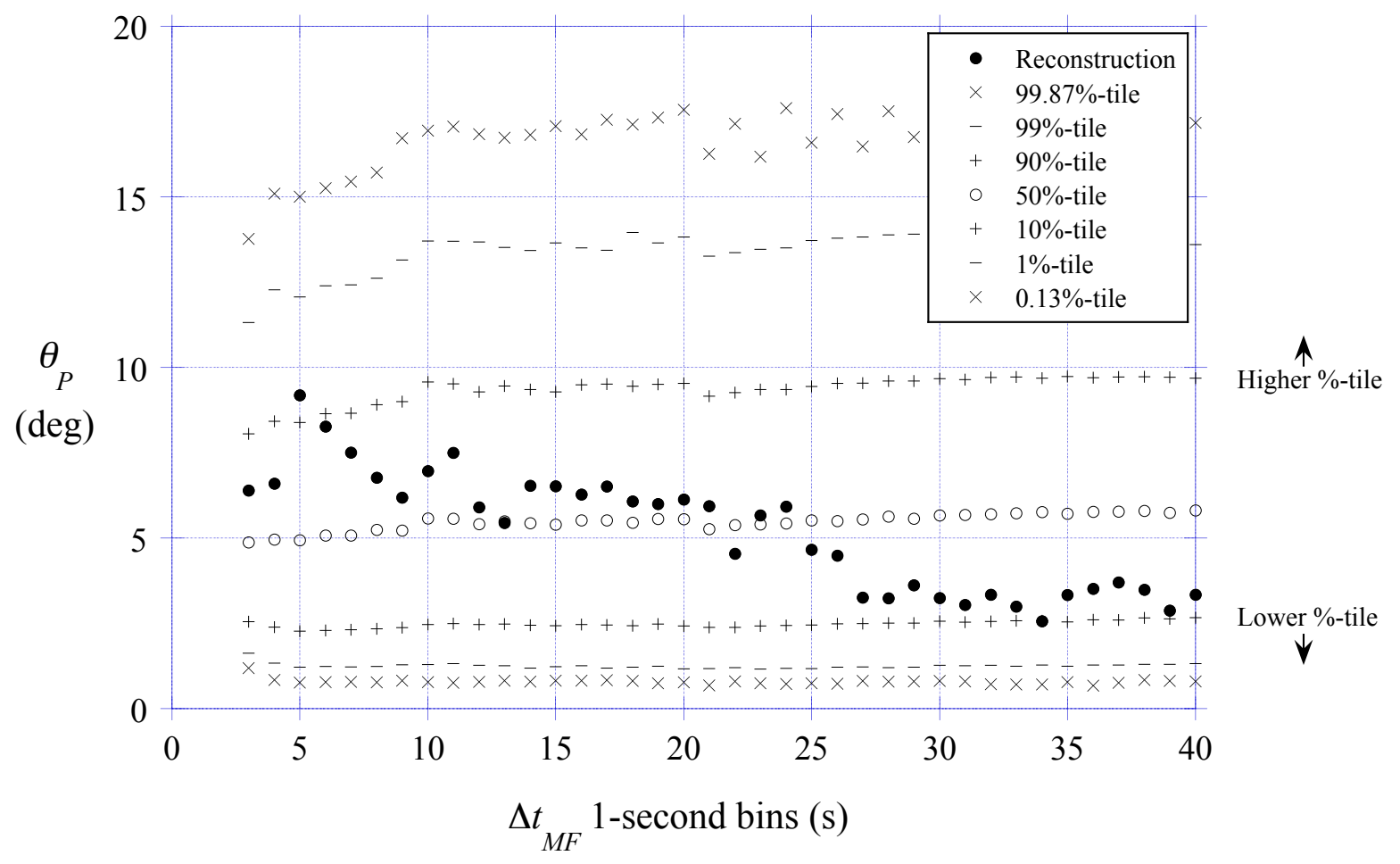

Figure 14. Maximum value of $\theta_{P}$ within one second bins, starting with the bin for $2 \mathrm{~s}<\Delta t_{M F} \leq 3 \mathrm{~s}$. The symbols are placed at the end of the one-second bins. The solid circles denote the reconstruction values. The other symbols show the results from an 8,000-trial Monte Carlo simulation run, presented in terms of percentiles.

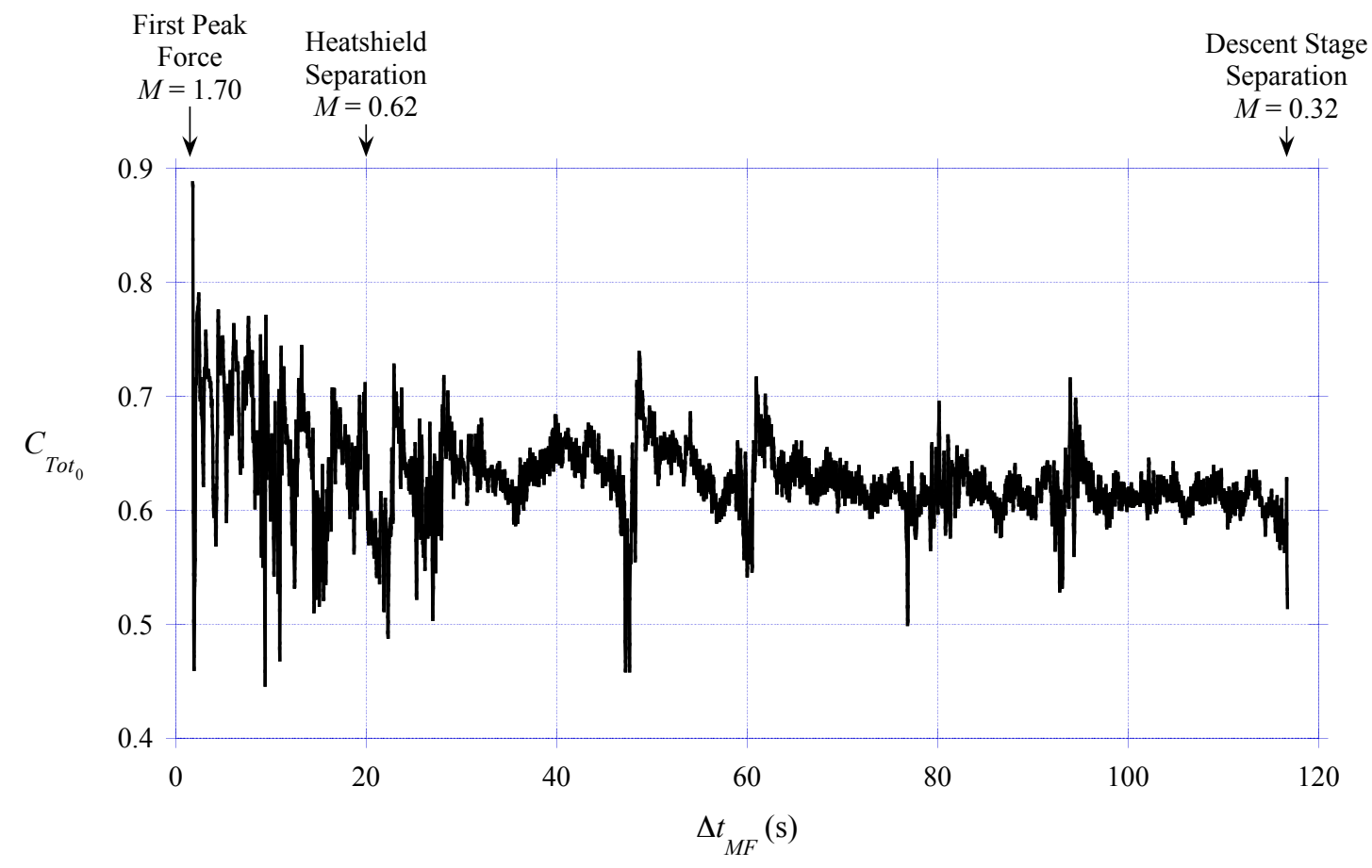

Figure 15. Parachute total force coefficient, $C_{T t_{0}}$ vs. time since mortar fire, $\Delta t_{M F}$. 


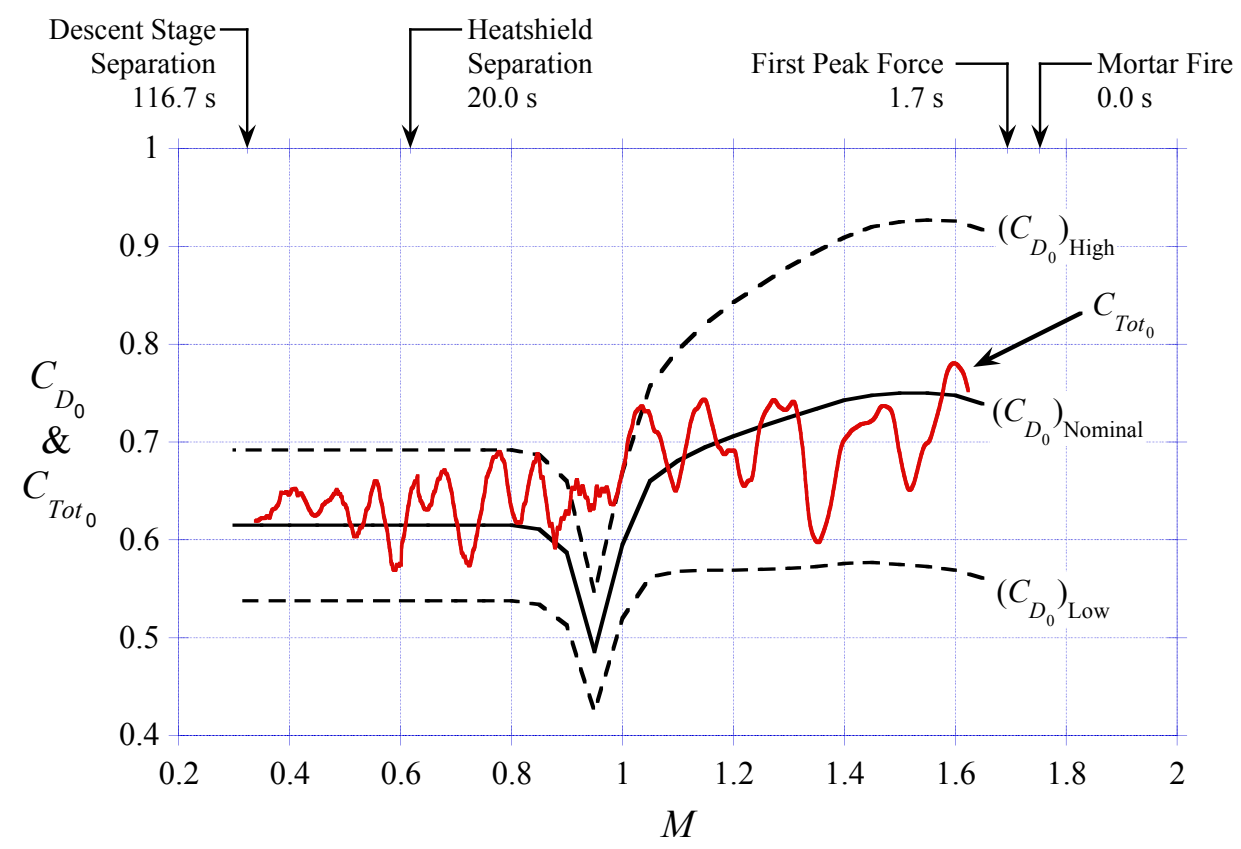

Figure 16. Reconstructed Mach number running average total parachute force coefficient, $C_{\text {Tot }_{0}}$ (solid red line), and the parachute drag coefficient model, $C_{D_{0}}$ (black solid and dashed lines), vs. Mach number, $M$. The running average for $C_{\text {Tot }}$ is centered at the specific Mach number, with a window of $\Delta M=0.03$ total width. 